\title{
BELIEF-FUNCTION FORMULAS FOR AUDIT RISK
}

\author{
Rajendra P. Srivastava* \\ and \\ Glenn R. Shafer ${ }^{* *}$
}

*Associate Professor of Accounting, and Deloitte \& Touche Faculty Fellow; **Ronald G. Harper Distinguished Professor of Business, School of Business, University of Kansas, Summerfield Hall, Lawrence, Kansas 66045-2003.

This research has been supported in part by grants from the Peat Marwick Foundation, the General Research Fund of the University of Kansas, and the National Science Foundation (grant IRI8902444). The authors would like to thank Andrew D. Bailey, Jr., Peter Gillett, Lynford E. Graham, William R. Kinney, Jr., Prakash P. Shenoy, W. R. Scott, Ira Solomon, and John Willingham for valuable comments on an earlier version of the article. 


\section{BELIEF-FUNCTION FORMULAS FOR AUDIT RISK}

SYNOPSIS AND INTRODUCTION: This article relates belief functions to the structure of audit risk and provides formulas for audit risk under certain simplifying assumptions. These formulas give plausibilities of error in the belief-function sense.

We believe that belief-function plausibility represents auditors' intuitive understanding of audit risk better than ordinary probability. The plausibility of a statement, within belief-function theory, measures the extent to which we lack evidence against the statement. High plausibility for error indicates only a lack of assurance, not positive evidence that there is error. Before collecting, analyzing, and aggregating the evidence, an auditor may lack any assurance that a financial statement is correct, and in this case will attribute very high plausibility to material misstatement. This high plausibility does not necessarily indicate any evidence that the statement is materially misstated, and hence it is inappropriate to interpret it as a probability of material misstatement.

The SAS No. 47 formula for audit risk is based on a very simple structure for audit evidence. The formulas we derive in this article are based on a slightly more complex but still simplified structure, together with other simplifying assumptions. We assume a tree-type structure for the evidence, assume that all evidence is affirmative and that each variable in the tree is binary. All these assumptions can be relaxed. As they are relaxed, however, the formulas become more complex and less informative, and it then becomes more useful to think in terms of computer algorithms rather than in terms of formulas (Shafer et al. 1988).

In general, the structure of audit evidence corresponds to a network of variables. We derive formulas only for the case in which each item of evidence bears either on all the audit objectives of an account or on all the accounts in the financial statement, as in figure 1, so that the network is a tree. Usually, however, there will be some evidence that bears on some but not all objectives for an account, on some but not all accounts, or on objectives at different levels; in this case, the network will not be a tree. 
We assume that all evidence is affirmative because this is the situation treated by the SAS No. 47 formula and because belief-function formulas become significantly more complex when affirmative and negative evidence is combined. This complexity is due primarily to the renormalization involved in Dempster's rule for combining belief functions.

The variables in the network or tree represent various audit objectives, accounts, and the financial statement as a whole. We assume these variables are binary. For example, we assume that an account either is or is not materially misstated. This assumption is clearly too restrictive for most audit practice. Often, for example, an auditor must consider immaterial errors in individual accounts that could produce a material error in the financial statement when they are aggregated.

We derive formulas for plausibility of material misstatement at three levels: the financial statement level, the account level, and the audit objective level. The formula at the audit objective level resembles the SAS No. 47 formula, ${ }^{1}$ but the formulas at the other two levels are significantly different. Because our model does distinguish evidence gathered at the three different levels, audits based on our formulas are sometimes significantly more efficient ${ }^{2}$ than audits based on the SAS No. 47 model or on the simpler Bayesian models.

Key Words: Audit risk, Belief functions, Planning model, Evaluation model 
The remainder of this article is divided into seven sections and two appendices. In section I, we review the existing literature on the audit risk model. In section II, we review the structure of various types of audit evidence. In section III, we review the belief-function treatment of audit evidence and discuss using belief-function plausibility to represent audit risk. In section IV, we discuss the combination of beliefs (or $\mathbf{m}$-values) at each level of the financial statement. This combination corresponds to aggregating the evidence that bears directly on the objectives at those levels. In section V, we present total plausibility formulas (i.e., belieffunction formulas for the total audit risk) and numerical examples. In section VI, we highlight the limitations of our formulas and suggest future directions for research. In section VII, we summarize our results. We review the propagation of belief functions in a tree in appendix A, and we use these results to derive the belief-function formulas for the total audit risk in appendix B.

\section{Review of the Literature}

Here we will review the existing literature on audit risk formulas and the difficulties involved in interpreting the numbers in these formulas as probabilities.

Although the model of SAS No. 47 (AICPA 1983) has been used for planning purposes since June 1984, controversy about its applicability for planning and evaluation has persisted. Graham points out, for example, that "overall assessments of audit risk for the financial statements taken as a whole are usually impractical for audit planning and engagement control" (1985a, 14), since inherent and control risks can vary from one account to another and from one class of transactions to another. Graham further suggests that the audit-risk model should be decomposed into components that determine audit risk for management assertions related to each account balance (accounts receivable, inventory, etc.) or class of transactions (purchases, sales, etc.). Cushing and Loebbecke (1983) argue that the SAS No. 47 model provides no guidance on aggregating risks associated with various account balances, and Kinney (1989) has demonstrated recently that the model has properties that may significantly understate achieved audit risk. 
Bayesian models have also been discussed in the literature for risk aggregation (see, e.g., Kinney 1984; Leslie 1984). The simplest Bayesian models do not consider different levels of the account, but Boritz and Jensen (1985) discuss the hierarchical structure of audit evidence and propose ways to combine such evidence by using probabilities to represent risks. Also, in discussing their assertion-based approach to auditing, Leslie et al. (1986) recognized the importance of the structure of audit evidence and emphasized that assurances from various items of evidence should be assessed at the management assertion level of the account and then combined. They considered the relationship between various accounts (e.g., accounts receivable depends on sales and cash receipts) in the aggregation process, but they assumed that the different items of evidence for different accounts were independent ${ }^{3}$.

At a qualitative level, there has been increasing recognition of the importance of the structure of evidence and its relation to various audit objectives in assessing control risk. In SAS No. 55 entitled "The Auditor's Responsibility for Assessing Control Risk" (AICPA 1988a, para. 3), we find the following statement:

After obtaining this understanding, the auditor assesses control risk for the assertions embodied in the account balance, transaction class, and disclosure components of the financial statements.

Although the AICPA has not yet required auditors to consider individual audit objectives when assessing other risks (e.g., inherent risk and detection risk), it appears that many are already doing so (Graham 1985a-1985e).

Boritz and Wensley (1990) have used the structure of audit evidence to develop their computer system for audit planning and evaluation, but their system uses heuristic rules rather than formal theory to combine uncertainties. Since such heuristics have been seen to fail in complex systems (Buchanan and Shortliffe 1984), we believe that more needs to be done to develop theoretical methods of combination that take account of the complexity of the structure of audit evidence.

We advance belief functions as a basis for this theoretical development because we believe that the usefulness of the Bayesian approach is limited by divergences between the intuitive and Bayesian interpretations of audit risk. For example, according to SAS No. 47, if an 
auditor decides not to consider inherent factors, then the inherent risk is set equal to 1 . Since a probability of 1 means certainty, this seems to be saying that it is certain that the account is materially in error. But this is not what the auditor has in mind when deciding not to depend on inherent factors. The auditor's intention is represented better by a belief-function plausibility of 1 for material error, which says only that the auditor lacks evidence based on inherent factors.

In a less extreme situation, the auditor may believe, on the basis of inherent factors, that the account is fairly stated and yet be unwilling to rely on these factors past a certain point. In this case, the auditor may, as SAS No. 47 suggests, assign a value less than the maximum, say 70 percent, to inherent risk. If interpreted in probability terms, this number says that the inherent factors give a 30 percent chance that the account is not materially misstated and a 70 percent chance that it is materially misstated. This suggests that the evidence is negative, contrary to the auditor's intuition. The probability interpretation is even more confusing if the auditor sets the inherent risk at 50 percent. What does this mean? Does it mean that the auditor is completely ignorant about the state of the account, or does it mean there is more evidence that the account is not being materially misstated than when only 30 percent assurance was assumed?

Belief functions, since they permit uncommitted belief, allow us to interpret the auditor's choices in a straightforward way. When the auditor sets the risk at 70 percent, a 30 percent degree of support from inherent factors is claimed, leaving 70 percent of the auditor's belief uncommitted. In this case, material misstatement has 70 percent plausibility, but absence of material misstatement has 100 percent plausibility. When the auditor sets the risk at 50 percent, stronger support from inherent factors is claimed. In this case, the plausibility of material misstatement is reduced to 50 percent, while the plausibility of no material misstatement remains at 100 percent.

We believe that belief functions provide a flexible and adaptable way to combine evidence from a variety of sources (Akresh et al. 1988). One aspect of this flexibility is that, when the belief functions representing individual items of evidence are probability measures, the belief-function analysis reduces to a Bayesian analysis (Shafer and Srivastava 1990). 


\section{The Structure of Audit Evidence}

As we have seen, neglect of the structure of audit evidence has been a problem in some risk models. Before developing belief-function formulas we must, therefore, specify carefully the kind of structure we are considering.

We will adopt the structure currently assumed in auditing standards (AICPA 1988a; see also, e.g., Arens and Loebbecke 1988), with some simplifications. The standards generally divide audit evidence into four categories: (1) general knowledge about inherent risk, (2) evidence from analytical procedures, (3) knowledge of control factors and accounting systems, and (4) tests of details of balances. Within each general category, further structure arises because of the relevance of different items of evidence to different accounts and different objectives. In the following subsections, we review the structure within each of the four categories.

\section{General Knowledge about Inherent Risk}

In this category, we include general knowledge about risk factors that lie outside of the accounting system and also outside of the auditor's control. Examples include economic, political, business and regulatory environments, experience from the prior year's audit, management philosophy and style, organizational structure, and audit committee (see SAS No. 55 for more examples). Also included in this category are factors that make individual accounts more or less susceptible to error, such as the complexity of transactions, the volume of transactions processed, the susceptibility of assets to defalcation, and related party transactions. Such factors are important for the auditor's planning decisions, since the extent, nature, and timing of tests will depend on the auditor's assessment of the effect of these factors on the individual accounts and on the financial statement as a whole.

Some inherent factors affect entire financial statements, whereas others affect only certain accounts or classes of transactions. Some affect only a particular audit objective for an account or a class of transactions. Information about the competence and integrity of management, for example, will affect the entire financial statement. The auditor will have a higher 
level of assurance about the financial statement when management is of recognized competence and integrity than when management is known to have been involved previously in irregularities. In contrast, an auditor auditing a newspaper publisher realizes that libel suits against newspapers are common and will treat this knowledge as evidence affecting only accrued-contingent liability. The nature and complexity of an individual account (e.g., susceptibility to defalcation, volume of transactions, non-routine transactions, account balance based on management's judgment) also may affect only that account. As an example of evidence that affects only a certain audit objective, we might cite information about related party transactions from the minutes of board meetings. This information affects only the disclosure and classification objectives of the accounts involved in the transaction.

In summary, we see that evidence about inherent factors can bear on the financial statement at three different levels: (1) the financial statement level, (2) the individual account or class of transactions level, and (3) the audit objective level for individual accounts or classes of transactions. See figure 1 for details. 
Figure 1

An Evidential Network

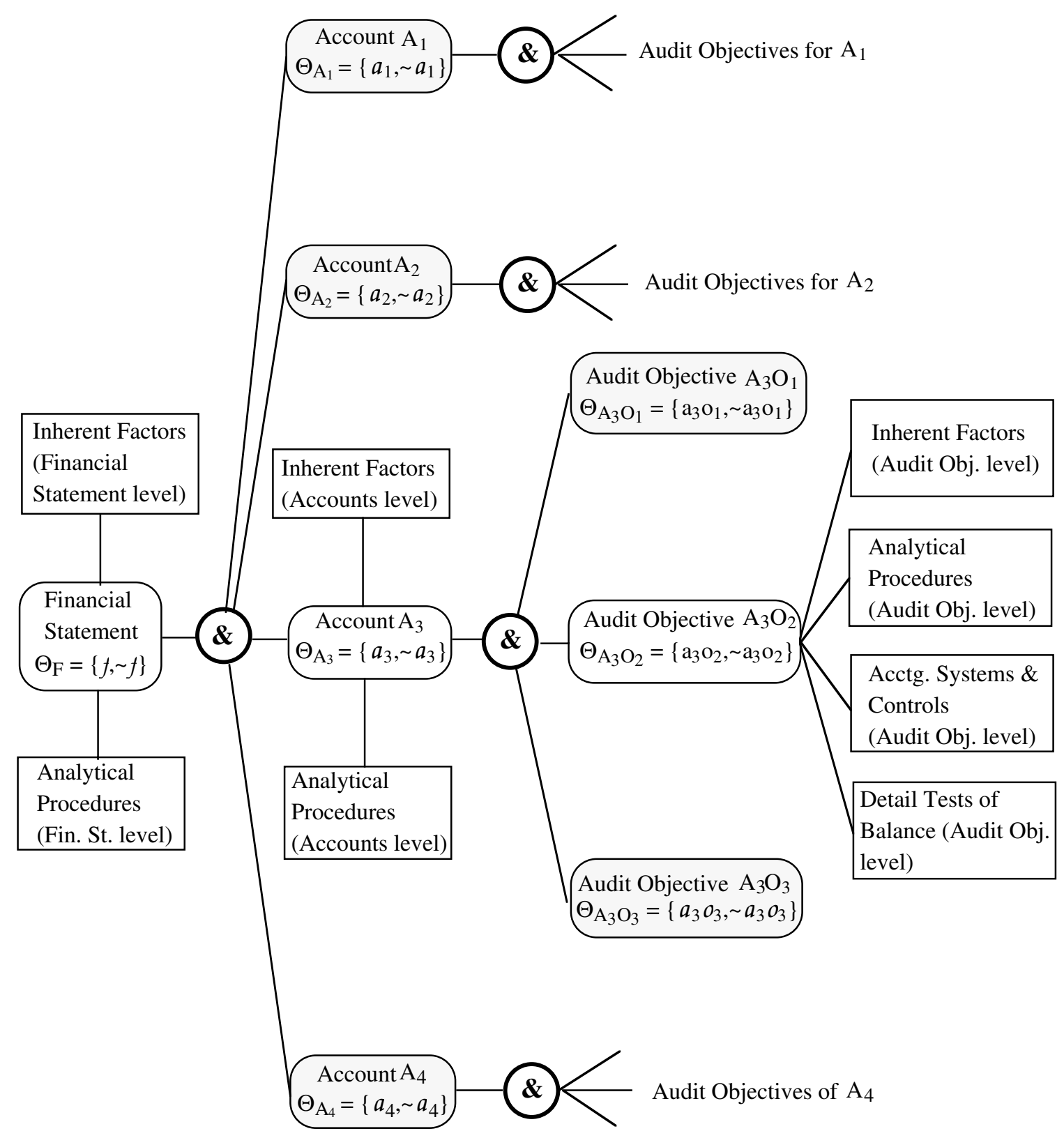

Note: A rounded rectangle represents a variable (variables being the financial statements as a whole, various accounts, and the related audit objectives). A rectangle represents an item of audit evidence. The evidence is connected to a variable that it directly supports. A circle with ' $\&$ ' implies that the variable on the left is true if and only if the variables on the right of the circle are true. 


\section{Analytical Procedures}

Recently, the AICPA published SAS No. 56 (AICPA 1988b), requiring auditors to use analytical procedures on all audit engagements. According to SAS No. 56 (para. 2),

Analytical procedures are an important part of the audit process and consist of evaluations of financial information made by a study of plausible relationships among both financial and non-financial data. Analytical procedures range from simple comparisons to the use of complex models involving many relationships and elements of data.

The statement proposes that analytical procedures be used for the following purposes (para. 4):

1. To assist the auditor in planning the nature, timing and extent of other auditing procedures.

2. As a substantive test to obtain evidential matter about particular assertions related to account balances or class of transactions.

3. As an overall review of the financial information in the final review stage of the audit.

According to SAS No. 56, the expected effectiveness and efficiency of an analytical procedure depends on (1) the nature of the audit objectives, (2) the plausibility and predictability of the relationship, (3) the reliability and availability of the data used to develop the expectation, and (4) the precision of the expectation.

Like general knowledge about inherent factors, analytical procedures can provide assurance at various levels. The more common analytical procedures seem to provide assurance at either the account level or the audit objective level. A comparison of the previous year's accounts payable with the current period's accounts payable provides assurance for the accounts payable balance as a whole. A comparison of the previous year's ratio of bad debt expense to accounts receivable balance with the current year's ratio would bear on collectibility of accounts receivable, a valuation objective.

In the present article, for the purpose of completeness, we will assume analytical procedures to be effective at all three levels: (1) the financial statement level, (2) the account or class of transactions level, and (3) the audit objective level for accounts or classes of transactions. When certain items of evidence are not to be considered in an audit, then those items are eliminated by setting the corresponding plausibilities to 1 (see the discussion in section V). 


\section{Control Factors and Accounting Systems}

We include in this category all items of evidence related to accounting systems, control procedures, and tests of transactions. A test of controls typically bears on the audit objective level of an individual account, while a test of transactions typically bears on the audit objective level of a class of transactions. Controls built into a cost accounting system, for example, bear on the valuation objective of inventory, while the use of prenumbered bills of lading and sales invoices periodically accounted for bears on the completeness objective of sales.

\section{Tests of Details of Balances}

Tests of details of balances bear primarily on the audit objective level. Since it is costly to obtain this type of evidence, the auditor minimizes the need for it by maximizing the assurance to accounts and audit objectives from other sources.

Some tests of details of balance bear on only one audit objective, while others may bear

on more than one. A review of the minutes of board meetings to check whether receivables have been factored bears only on the ownership objective of accounts receivable, but confirmations of accounts receivable by customers provide assurance for both the existence and valuation objectives. In general, such assurances may vary in strength from objective to objective. For example, confirmation of accounts receivable may provide a higher level of support for the existence objective than for the valuation objective.

When an item of evidence bears equally on all the objectives of an account or all the accounts of the financial statement, we can represent it within a tree structure by linking it directly to the account or the financial statement, as the case may be. But when a test provides support to more than one audit objective, say, but not equally to all the objectives at once, we obtain a network of variables that is not a tree, and this makes the derivation of formulas cumbersome. The formulas given here are based on the assumption that the network is a tree, but they can be used as approximations in the non-tree case. One way to use them as approximations is to treat the evidence as if it consisted of independent items of evidence bearing on the different objectives. 
The formula for the total audit risk (i.e., total plausibility of error) at the audit objective level will still be valid (i.e., it maintains its multiplicative form; see section V) when we do this, but the formulas at the account level and the financial statement level will provide only a conservative estimate of the total risk (i.e., plausibility of error). For example, suppose that confirmations of accounts receivable yield 0.9 level of assurance that both existence and valuation objectives are met. If we treat this as two items of evidence, one giving 0.9 degree of support for existence and one giving 0.9 for valuation, then our formulas give a total assurance, for the two objectives jointly, of 0.9 x $0.9=0.81$, corresponding to a risk (plausibility of error) of 0.19 . But the correct value for the assurance is 0.9 , corresponding to a risk of 0.1 .

\section{Belief-function Approach to Audit Evidence}

In this section, we review the belief-function approach to representing uncertainties in audit evidence. The belief-function framework involves three related representations for beliefs concerning a topic: the belief function (Bel), the plausibility function $(\mathbf{P L})$, and the basic probability assignment (m). As we will explain, the basic probability assignment is often convenient for expressing initial judgments, but the plausibility function is useful for expressing final judgements about audit risk.

The basic probability assignment is also called the $\mathbf{m}$-function, and its values are called $\mathbf{m}$-values (Shafer 1976). The basic difference between $\mathbf{m}$-values and probabilities is that probabilities are assigned to individual elements of a frame, ${ }^{4}$ say $\Theta$, whereas $\mathbf{m}$-values are assigned to a subset of elements of the frame. The sum of all the $\mathbf{m}$-values for all the subsets of the frame $\Theta$ is 1 . Formally, the $\mathbf{m}$-function assigns a number $\mathbf{m}(\mathrm{B})$ to each subset $\mathrm{B}$ of $\Theta$ such that $\mathbf{m}(\varnothing)=0$ ( $\varnothing$ being the empty set) and

$$
\sum_{B \subseteq \Theta} \mathbf{m}(B)=1
$$

There are two ways to obtain $\mathbf{m}$-values on a frame: (1) they may be assigned directly by the decision maker on the basis of subjective judgment and (2) they may be derived from a com- 
patibility relationship between a frame with known probabilities and the frame of interest. ${ }^{5} \mathrm{We}$ will use the first approach to discuss our example.

Suppose the auditor has performed a set of analytical procedures appropriate to account 'A' and finds no discrepancy or errors in the account. On the basis of this observation, the auditor feels that the evidence is positive and provides a medium level of support, say 0.6 , to ' $a$ ' that the account is not materially misstated. ${ }^{6}$ However, at the same time, the auditor feels that there is nothing to indicate that the account is materially misstated $(\sim a)$. This means that 0.6

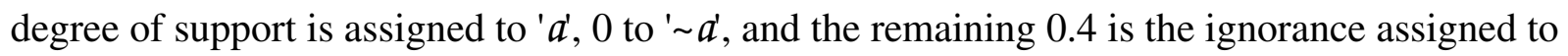
the entire frame $\Theta=\{a, \sim a\}$; that is,

$$
\mathbf{m}_{\mathrm{PA}}(a)=0.6, \mathbf{m}_{\mathrm{PA}}(\sim a)=0, \text { and } \mathbf{m}_{\mathrm{PA}}(a, \sim a)=0.4
$$

where the subscript PA stands for analytical procedures at the account level. The above set of m-values represents affirmative evidence. ${ }^{7}$

As mentioned earlier, we will consider only affirmative evidence in our derivation of audit risk formulas. Although the approach of aggregating evidence discussed in this article is valid for any type of evidence, use of affirmative evidence avoids the renormalization procedure 8 in aggregating various items of evidence and thus yields simple analytical formulas.

Let us go back to our example of analytical procedures discussed above and express the auditor's judgment about the level of support obtained (or to be obtained when planning the audit) from the procedures for account 'A' in terms of algebraic expressions:

$$
\begin{gathered}
\mathbf{m}_{\mathrm{PA}}(a)=1-\mathrm{APR}_{\mathrm{A}}, \\
\mathbf{m}_{\mathrm{PA}}(\sim a)=0,
\end{gathered}
$$

and

$$
\mathbf{m}_{\mathrm{PA}}(\{a, \sim a\})=\mathrm{APR}_{\mathrm{A}},
$$

where $\mathrm{APR}_{\mathrm{A}}$ represents a number. Equation (1) implies that the analytical procedures performed by the auditor for account 'A' provide assurance that the account is not materially misstated with $\left(1-\mathrm{APR}_{\mathrm{A}}\right)$ degree of support. 
Belief Functions and Plausibility Functions

In general, the total belief in a subset $\mathrm{B}$ of the frame $\Theta$ is given by:

$$
\operatorname{Bel}(\mathrm{B})=\sum_{\mathrm{X} \subseteq \mathrm{B}} \mathbf{m}(\mathrm{X}),
$$

where $\mathrm{X}$ represents a set of elements of $\Theta$, and the plausibility of $\mathrm{B}$ is given by

$$
\mathbf{P L}(\mathrm{B})=\sum_{\mathrm{B} \cap \mathrm{X} \neq \varnothing} \mathbf{m}(\mathrm{X})=1-\operatorname{Bel}(\sim \mathrm{B}) .
$$

Intuitively, the plausibility of B is the degree to which B is plausible in the light of the evi-

dence - the degree to which we do not disbelieve B or assign belief to its negation $\sim \mathrm{B}$. Complete ignorance or lack of opinion about B is represented by $\operatorname{Bel}(B)=0$ and $\mathbf{P L}(B)=1$.

Consider again the numerical example discussed above. We have $\mathbf{m}_{\mathrm{PA}}(a)=0.6$, $\mathbf{m}_{\mathrm{PA}}(\sim a)=0$, and $\mathbf{m}_{\mathrm{PA}}(a, \sim a)=0.4$. From (4) and (5), we obtain

$$
\begin{gathered}
\operatorname{Bel}_{\mathrm{PA}}(a)=\mathbf{m}_{\mathrm{PA}}(a)=0.6, \\
\operatorname{Bel}_{\mathrm{PA}}(\sim a)=\mathbf{m}_{\mathrm{PA}}(\sim a)=0, \\
\operatorname{Bel}_{\mathrm{PA}}(\{a, \sim a\})=\mathbf{m}_{\mathrm{PA}}(a)+\mathbf{m}_{\mathrm{PA}}(\sim a)+\mathbf{m}_{\mathrm{PA}}(a, \sim a)=0.6+0+0.4=1.0,
\end{gathered}
$$

and

$$
\begin{gathered}
\mathbf{P L}_{\mathrm{PA}}(a)=1-\mathbf{B e l}_{\mathrm{PA}}(\sim a)=1 \\
\mathbf{P L}_{\mathrm{PA}}(\sim a)=1-\mathbf{B e l}_{\mathrm{PA}}(a)=1-0.6=0.4 .
\end{gathered}
$$

The intuitive meaning of $\operatorname{Bel}_{\mathrm{PA}}(a)=0.6$ is that the auditor has direct evidence from analytical procedures relevant to account 'A' that ' $a$ ' is true with 0.6 degree of support (i.e., the account is not materially misstated with degree 0.6). $\operatorname{Bel}_{\mathrm{PA}}(\sim a)=0$ means that the auditor has no evidence from analytical procedures that the account is materially misstated (i.e., $\sim a$ is true).

Let us now consider $\mathbf{P L}_{\mathrm{PA}}(a)=1$. What does it mean? We know that analytical procedures provide no belief to $\sim a\left(\operatorname{Bel}_{\mathrm{PA}}(\sim a)=0\right)$. Since there is no support committed to just $\sim a$, all the probability mass could be assigned to $a$, which implies that $\mathbf{P L}_{\mathrm{PA}}(a)=1$. Similarly, since $\operatorname{Bel}_{\mathrm{PA}}(a)=0.6$ (i.e., 0.6 degree of belief is directly committed to $a$ ), the remaining amount 0.4 of uncommitted probability mass could be assigned to $\sim a$; that is, $\mathbf{P L}_{\mathrm{PA}}(\sim a)=0.4$. 
Going back to the $\mathbf{m}$-values in equations (1) - (3), we obtain the following beliefs and plausibilities:

$$
\operatorname{Bel}_{\mathrm{PA}}(a)=1-\mathrm{APR}_{\mathrm{A}}, \mathbf{B e l}_{\mathrm{PA}}(\sim a)=0 \text {, and } \operatorname{Bel}_{\mathrm{PA}}(\{a, \sim a\})=1,
$$

and

$$
\mathbf{P L}_{\mathrm{PA}}(a)=1 \text {, and } \mathbf{P L}_{\mathrm{PA}}(\sim a)=\operatorname{APR}_{\mathrm{A}} .
$$

The plausibility function, $\mathbf{P L}_{\mathrm{PA}}(\sim a)=\mathrm{APR}_{\mathrm{A}}$, has an important interpretation. It provides a non-frequentist interpretation of the auditing concept of risk. This is a measure of how risky we feel it would be to stop with this evidence. According to the analytical procedures performed at the account level, we have $\left(1-\mathrm{APR}_{\mathrm{A}}\right)$ degree of belief that $a$ is true, leaving a plausibility of $\mathbf{P L}_{\mathrm{PA}}(\sim a)=\mathrm{APR}_{\mathrm{A}}$ that the account is materially misstated. This is the audit risk associated with the analytical procedures performed at the account level (see table 1 for definitions of other risks).

Table 1

\section{List of Symbols and Their Definitions}

\section{Propositions}

$a \quad$ - Account 'A' is not materially misstated.

$\sim a \quad-$ Account ' $\mathrm{A}$ ' is materially misstated.

$f \quad$ - The financial statement, $\mathrm{F}$, is not materially misstated.

$\sim f \quad$ - The financial statement, $\mathrm{F}$, is materially misstated.

ao - There is no material misstatement related to objective 'O' of account 'A'.

$\sim a o \quad-$ There is material misstatement related to objective ' $\mathrm{O}$ ' of account 'A'.

m-Functions, Belief Functions, and Plausibility Functions

$\mathbf{m}_{\mathrm{A}}() \quad-.\mathbf{m}$-values at the level of account $\mathrm{A}$ for the proposition(s) in the argument.

$\mathbf{m}_{\mathrm{F}}($.) $\quad$ - $\mathbf{m}$-values at the level of the financial statement for the proposition(s) in the argument.

$\mathbf{m}_{\mathrm{AO}}($.$) - \mathbf{m}$-values at the level of the audit objective $\mathrm{O}$ of account $\mathrm{A}$ for the proposition(s) in the argument.

$\mathbf{m}_{\mathrm{CO}}($.$) - \mathbf{m}$-values obtained from internal controls and accounting systems at the audit objective level for the proposition(s) in the argument.

$\mathbf{m}_{\mathrm{DO}}($.$) - \mathbf{m}$-values obtained from detailed test of balance at the audit objective level for the proposition(s) in the argument.

$\mathbf{m}_{\mathrm{IA}}($.$) \quad - \mathbf{m}$-values obtained from inherent factors at the account level for the proposition(s) in the argument. 

$\mathbf{m}_{\mathrm{IO}}(.) \quad \mathbf{m}$-values obtained from inherent factors at the audit objective level for the proposi- tion(s) in the argument.
$\mathbf{m}_{\mathrm{IF}}() \quad-.\mathbf{m}$-values obtained from inherent factors at the financial statement level for the proposition(s) in the argument.
$\mathbf{m}_{\mathrm{PA}}() \quad-.\mathbf{m}$-values obtained from analytical procedures performed at the account level for the proposition(s) in the argument.
$\mathbf{m}_{\mathrm{PF}}($.$) \quad - \mathbf{m}$-values obtained from analytical procedures performed at the financial statement level for the proposition(s) in the argument.
$\mathbf{m}_{\mathrm{PO}}($.) - $\mathbf{m}$-values obtained from analytical procedures performed at the audit objective level for the proposition(s) in the argument.
Bel $_{X}($.$) - A belief function, x$ represents various indices as described above in the case of $\mathbf{m}$.
$\mathbf{P L}_{\mathbf{X}}($.$) - A plausibility function, \mathrm{x}$ again represents various indices as described in the case of m.

Plausibility Functions for Material Misstatements

(i.e., Audit Risks* in Belief-Function Framework)

$\mathrm{IR}_{\mathrm{AO}} \quad$ - Plausibility of material misstatement in objective 'O' of account 'A' obtained from inherent factors at ' $\mathrm{O}$ ' of ' $\mathrm{A}$ ', or the risk (in the belief-function framework) associated with inherent factors at 'O' of account 'A'.

$\mathrm{CR}_{\mathrm{AO}}$ - Control risk (plausibility of material misstatement on the basis of internal controls and accounting systems) for account ' $\mathrm{A}$ ' at audit objective ' $\mathrm{O}$ '.

$\mathrm{APR}_{\mathrm{AO}}$ - The risk associated with analytical procedures performed at the audit objective level.

$\mathrm{DR}_{\mathrm{AO}} \quad$ - The risk associated with detailed test of balance for account 'A' at objective 'O'.

$\mathrm{AR}_{\mathrm{AO}}=\mathrm{IR}_{\mathrm{AO}} \mathrm{APR} \mathrm{AO}_{\mathrm{AO}} \mathrm{CR}_{\mathrm{AO}} \mathrm{DR}_{\mathrm{AO}}$, audit risk at the audit objective level when considering only the items of evidence that directly support the audit objective 'O' of account 'A'.

$I_{A} \quad$ - The risk associated with inherent factors at the account level.

$\mathrm{APR}_{\mathrm{A}}$ - The risk associated with analytical procedures performed at the account level.

$\mathrm{IR}_{\mathrm{F}} \quad$ - The risk associated with inherent factors at the financial statement level.

$\mathrm{APR}_{\mathrm{F}} \quad$ - The risk associated with analytical procedures performed at the financial statement level.

$\mathrm{AR}_{\mathrm{AO}}^{\mathrm{t}}=\mathrm{IR}_{\mathrm{F}} \mathrm{APR} \mathrm{R}_{\mathrm{F}} \mathrm{IR}_{\mathrm{A}} \mathrm{APR} \mathrm{A}_{\mathrm{A}} \mathrm{AR}$ AO, total audit risk at the objective level considering all the items of evidence.

$\mathrm{AR}_{\mathrm{A}}^{\mathrm{t}}=\mathrm{IR}_{\mathrm{F}} \mathrm{APR} \mathrm{F}_{\mathrm{F}} \mathrm{IR}_{\mathrm{APR}} \mathrm{A}\left[1-\Pi\left(1-\mathrm{AR}_{\mathrm{AO}}\right)\right]$, total audit risk at the account level $\mathrm{O}$ considering all the items of evidence.

$\mathrm{AR}_{\mathrm{F}}^{\mathrm{t}}=\operatorname{IR}_{\mathrm{F}} \mathrm{APR}_{\mathrm{F}}\left[1-\prod_{\mathrm{A}}\left(1-\mathrm{AR}_{\mathrm{A}}\right)\right]$, total audit risk at the financial statement level.

* Note that we have used the term "risk" for plausibility of material misstatement in the table and also in the text. 
This plausibility interpretation of audit risk is conceptually in agreement with the thought process of the auditor when planning an audit. For example, if the auditor plans an audit of an account to obtain an overall assurance of 0.95 (i.e., Bel $(a)=0.95)$ that the account is not materially misstated then, in plausibility terms, it means that the auditor is planning the audit at the 0.05 level of plausibility for material error in the account (i.e., $\mathbf{P L}(\sim a)=0.05)$. In other words, if the auditor had to stop after obtaining 0.95 level of assurance that ' $a$ ' was true, then the evidence gathered up to that point would suggest that ' $\sim a$ ' is plausible with degree 0.05 ; that is, there is a maximum risk of 0.05 that the account is materially misstated. ${ }^{9}$

In general, $\mathbf{B e l}(\mathrm{B}) \leq \mathbf{P L}(\mathrm{B})$ for every subset $\mathrm{B}$ of our frame $\Theta$. If we believe $\mathrm{B}$, then we think B is plausible, but the converse is not necessarily true. A zero plausibility for a proposition means that we are sure that it is false (like a zero probability in the Bayesian theory), but a zero degree of belief for a proposition means only that we see no reason to believe the proposition.

Similar explanations can be given to the $\mathbf{m}$-values, belief functions, and plausibility functions for the other seven items of evidence presented in table 2. The individual $\mathbf{m}$-values given in table 2 combined with Dempster's rule (see n. 8) will give us the overall belief that the financial statement is fairly presented. Since these $\mathbf{m}$-values are defined at different nodes in an evidential network (e.g., see figure 1), combining them becomes a problem of propagating $\mathbf{m}$ values (or belief functions) through the network. We have discussed this problem in a working paper ${ }^{10}$ and have summarized the results in appendix A. 
Table 2

m-Values, Belief, and Plausibility Functions for Different Audit Evidence Given in Figure 1

\begin{tabular}{|c|c|c|c|}
\hline Evidence & m-values & Belief & Plausibility \\
\hline \multicolumn{4}{|l|}{ Audit Objective Level: } \\
\hline Inherent factors & $\begin{array}{l}\mathbf{m}_{\mathrm{IO}}(a o)=1-\mathrm{IR}_{\mathrm{AO}} \\
\mathbf{m}_{\mathrm{IO}}(\sim a o)=0 \\
\mathbf{m}_{\mathrm{IO}}(\{a o, \sim a o\})=\mathrm{IR}_{\mathrm{AO}}\end{array}$ & $\begin{array}{l}\operatorname{Bel}_{\mathrm{IO}}(a o)=1-\mathrm{IR}_{\mathrm{AO}} \\
\operatorname{Bel}_{\mathrm{IO}}(\sim a o)=0 \\
\operatorname{Bel}_{\mathrm{IO}}(\{a o, \sim a o\})=1\end{array}$ & $\begin{array}{l}\operatorname{PL}_{\mathrm{IO}}(a o)=1 \\
\mathbf{P L}_{\mathrm{IO}(\sim a o)=\mathrm{IR}_{\mathrm{AO}}}\end{array}$ \\
\hline Analytical procedures & $\begin{array}{l}\mathbf{m}_{\mathrm{PO}}(a o)=1-\mathrm{APR}_{\mathrm{AO}} \\
\mathbf{m}_{\mathrm{PO}(\sim a o)=0} \\
\mathbf{m}_{\mathrm{PO}}(\{a o, \sim a o\})=\mathrm{APR}_{\mathrm{AO}}\end{array}$ & $\begin{array}{l}\operatorname{Bel}_{\mathrm{PO}}(a o)=1-\mathrm{APR}_{\mathrm{AO}} \\
\operatorname{Bel}_{\mathrm{PO}}(\sim a o)=0 \\
\operatorname{Bel}_{\mathrm{PO}}(\{a o, \sim a o\})=1\end{array}$ & $\begin{array}{l}\operatorname{PL}_{\mathrm{PO}}(a o)=1 \\
\operatorname{PL}_{\mathrm{PO}}(\sim a o)=\mathrm{APR}_{\mathrm{AO}}\end{array}$ \\
\hline $\begin{array}{l}\text { Control factors and } \\
\text { accounting systems }\end{array}$ & $\begin{array}{l}\mathbf{m}_{\mathrm{CO}}(a o)=1-\mathrm{CR}_{\mathrm{AO}} \\
\mathbf{m}_{\mathrm{CO}}(\sim a o)=0 \\
\mathbf{m}_{\mathrm{CO}}(\{a o, \sim a o\})=\mathrm{CR}_{\mathrm{AO}}\end{array}$ & $\begin{array}{l}\operatorname{Bel}_{\mathrm{CO}}(a o)=1-\mathrm{CR}_{\mathrm{AO}} \\
\operatorname{Bel}_{\mathrm{CO}}(\sim a o)=0 \\
\operatorname{Bel}_{\mathrm{CO}}(\{a o, \sim a o\})=1\end{array}$ & $\begin{array}{l}\mathbf{P L}_{\mathrm{CO}}(a o)=1 \\
\mathbf{P L}_{\mathrm{CO}}(\sim a o)=\mathrm{CR}_{\mathrm{AO}}\end{array}$ \\
\hline Detailed tests of balance & $\begin{array}{l}\mathbf{m}_{\mathrm{DO}}(a o)=1-\mathrm{DR} \\
\mathbf{m}_{\mathrm{DO}}(\sim a o)=0 \\
\mathbf{m}_{\mathrm{DO}}(\{a o, \sim a o\})=\mathrm{DR}_{\mathrm{AO}}\end{array}$ & $\begin{array}{l}\operatorname{Bel}_{\mathrm{DO}}(a o)=1-\mathrm{DR}_{\mathrm{AO}} \\
\operatorname{Bel}_{\mathrm{DO}}(\sim a o)=0 \\
\operatorname{Bel}_{\mathrm{DO}}(\{a o, \sim a o\})=1\end{array}$ & $\begin{array}{l}\mathbf{P L}_{\mathrm{DO}}(a o)=1 \\
\mathbf{P L}_{\mathrm{DO}}(\sim a o)=\mathrm{DR}_{\mathrm{AO}}\end{array}$ \\
\hline \multicolumn{4}{|l|}{ Account Level: } \\
\hline Inherent factors & $\begin{array}{l}\mathbf{m}_{\mathrm{IA}}(a)=1-\mathrm{IR}_{\mathrm{A}} \\
\mathbf{m}_{\mathrm{IA}}(\sim a)=0 \\
\mathbf{m}_{\mathrm{IA}}(\{a, \sim a\})=\mathrm{IR}_{\mathrm{A}}\end{array}$ & $\begin{array}{l}\operatorname{Bel}_{\mathrm{IA}}(a)=1-\mathrm{IR}_{\mathrm{A}} \\
\operatorname{Bel}_{\mathrm{IA}}(\sim a)=0 \\
\operatorname{Bel}_{\mathrm{IA}}(\{a, \sim a\})=1\end{array}$ & $\begin{array}{l}\mathbf{P L}_{\mathrm{IA}}(a)=1 \\
\operatorname{PL}_{\mathrm{IA}}(\sim a)=\mathrm{IR}_{\mathrm{A}}\end{array}$ \\
\hline Analytical procedures & $\begin{array}{l}\mathbf{m}_{\mathrm{PA}}(a)=1-\mathrm{APR}_{\mathrm{A}} \\
\mathbf{m}_{\mathrm{PA}}(\sim a)=0 \\
\mathbf{m}_{\mathrm{PA}}(\{a, \sim a\})=\mathrm{APR}_{\mathrm{A}}\end{array}$ & $\begin{array}{l}\operatorname{Bel}_{\mathrm{PA}}(a)=1-\mathrm{APR}_{\mathrm{A}} \\
\operatorname{Bel}_{\mathrm{PA}}(\sim a)=0 \\
\operatorname{Bel}_{\mathrm{PA}}(\{a, \sim a\})=1\end{array}$ & $\begin{array}{l}\operatorname{PL}_{\mathrm{PA}}(a)=1 \\
\operatorname{PL}_{\mathrm{PA}}(\sim a)=\mathrm{APR}_{\mathrm{A}}\end{array}$ \\
\hline \multicolumn{4}{|c|}{ Financial Statement Level: } \\
\hline Inherent factors & $\begin{array}{l}\mathbf{m}_{\mathrm{IF}}(f)=1-\mathrm{IR}_{\mathrm{F}} \\
\mathbf{m}_{\mathrm{IF}}(\sim f)=0 \\
\mathbf{m}_{\mathrm{IF}}(\{f, \sim f\})=\mathrm{IR}_{\mathrm{F}}\end{array}$ & $\begin{array}{l}\operatorname{Bel}_{I F}(f)=1-\operatorname{IR}_{\mathrm{F}} \\
\operatorname{Be}_{I F}(\sim f)=0 \\
\operatorname{Be}_{I F}(\{f, \sim f\})=1\end{array}$ & $\begin{array}{l}\mathbf{P L}_{\mathrm{IF}}(f)=1 \\
\mathbf{P L}_{\mathrm{IF}}(\sim f)=\mathrm{IR}_{\mathrm{F}}\end{array}$ \\
\hline Analytical procedures & $\begin{array}{l}\mathbf{m}_{\mathrm{PF}}(f)=1-\mathrm{APR}_{\mathrm{F}} \\
\mathbf{m}_{\mathrm{PF}}(\sim f)=0 \\
\mathbf{m}_{\mathrm{PF}}(\{f, \sim f\})=\mathrm{APR}_{\mathrm{F}}\end{array}$ & $\begin{array}{l}\operatorname{Bel}_{\mathrm{PF}}(f)=1-\mathrm{APR}_{\mathrm{F}} \\
\operatorname{Bel}_{\mathrm{PF}}(\sim f)=0 \\
\operatorname{Bel}_{\mathrm{PF}}(\{f, \sim f\})=1\end{array}$ & $\begin{array}{l}\operatorname{PL}_{\mathrm{PF}}(f)=1 \\
\operatorname{PL}_{\mathrm{PF}}(\sim f)=\mathrm{APR}_{\mathrm{F}}\end{array}$ \\
\hline
\end{tabular}

Note: The symbols are defined in table 1. Each item of audit evidence is assumed to be affirmative. 


\section{IV. m-Values Directly Defined at Each Node}

To combine all the evidence in figure 1 , we need to combine the $\mathbf{m}$-values given in table 2. There are eight sets of $\mathbf{m}$-values (four at the audit objective level, two at the account level, and two at the financial statement level; see table 2). Combining these $\mathbf{m}$-values, in general, is very complex. However, the process is simplified if we proceed in two steps. First, we combine the $\mathbf{m}$-values directly bearing on each node in figure 1 . For example, we combine the $\mathbf{m}$-values obtained from the four items of evidence at the audit objective level. Similarly, the total $\mathbf{m}$ values bearing directly at the account level and the financial statement level will be the combination of two $\mathbf{m}$-values defined at each level. Second, we propagate the above $\mathbf{m}$-values obtained at each node using the results of appendix A. In the following paragraphs, we discuss the first step and provide analytical formulas for the resultant $\mathbf{m}$-values at each level.

\section{$\boldsymbol{m}$-Values at the Financial Statement Level}

We assume that the two items of evidence directly bearing at the financial statement level are: (1) inherent factors and (2) analytical procedures (see figure 1). We further assume that these items of evidence are affirmative in nature. The corresponding $\mathbf{m}$-values are given in table 2. Since there is no conflict among the evidence, we obtain the following values directly defined at the financial statement level using Dempster's rule (see n. 8):

$$
\begin{gathered}
\mathbf{m}_{\mathrm{F}}(f)=\mathbf{m}_{\mathrm{IF}}(f) \mathbf{m}_{\mathrm{PF}}(f)+\mathbf{m}_{\mathrm{IF}}(f) \mathbf{m}_{\mathrm{PF}}(\{f, \sim f\})+\mathbf{m}_{\mathrm{IF}}(\{f, \sim f\}) \mathbf{m}_{\mathrm{PF}}(f) \\
=\left(1-\mathrm{IR}_{\mathrm{F}}\right)\left(1-\mathrm{APR}_{\mathrm{F}}\right)+\left(1-\mathrm{IR}_{\mathrm{F}}\right) \mathrm{APR}_{\mathrm{F}}+\mathrm{IR}_{\mathrm{F}}\left(1-\mathrm{APR}_{\mathrm{F}}\right) \\
=1-\mathrm{IR}_{\mathrm{F}} \mathrm{APR}_{\mathrm{F}}, \\
\mathbf{m}_{\mathrm{F}}(\sim f)=\mathbf{m}_{\mathrm{IF}}(\sim f) \mathbf{m}_{\mathrm{PF}}(\sim f)+\mathbf{m}_{\mathrm{IF}}(\sim f) \mathbf{m}_{\mathrm{PF}}(\{f, \sim f\}) \\
+\mathbf{m}_{\mathrm{IF}}(\{f, \sim f\}) \mathbf{m}_{\mathrm{PF}}(\sim f)=0,
\end{gathered}
$$

and

$$
\mathbf{m}_{\mathrm{F}}(\{f, \sim f\})=\mathbf{m}_{\mathrm{IF}}(\{f, \sim f\}) \mathbf{m}_{\mathrm{PF}}(\{f, \sim f\})=\mathrm{IR}_{\mathrm{F}} \mathrm{APR}_{\mathrm{F}} .
$$

From the above results, one can generalize that if the frame consists of only two elements, such as $f$, and $\sim f$, and the $\mathbf{m}$-values for $\sim f$ are zero for all the evidence, then the combined 
$\mathbf{m}$-value for $\sim f$ will be zero, irrespective of the number of items of evidence, and the combined $\mathbf{m}$-value for the entire frame $\{f, \sim f\}$ will be the product of its $\mathbf{m}$-values from each item of evidence.

m-Values at the Account Level

As shown in figure 1, we consider two items of evidence at the account level: (1) inherent factors and (2) analytical procedures. Again, it is assumed that these items of evidence are affirmative in nature, and the corresponding $\mathbf{m}$-values are given in table 2 . The combined $\mathbf{m}$-values are similar to those in equations (8)-(10):

and

$$
\begin{gathered}
\mathbf{m}_{\mathrm{A}}(a)=1-\mathrm{IR}_{\mathrm{A}} \mathrm{APR}_{\mathrm{A}}, \\
\mathbf{m}_{\mathrm{A}}(\sim a)=0,
\end{gathered}
$$

m-Values at the Audit Objective Level

In general, there are four items of evidence at the audit objective level (see figure 1). Again, assume that they are all affirmative in nature. Then the corresponding $\mathbf{m}$-values can be given as in table 2. We want to combine all the $\mathbf{m}$-values obtained from these items of evidence. Since the $\mathbf{m}$-values for $\sim a o$ for all the evidence are assumed to be zero, the combined $\mathbf{m}$-value for $\sim a o$ is zero (see equation [9]), that is,

$$
\mathbf{m}_{\mathrm{AO}}(\sim a o)=0
$$

Also, as seen in (10), since there is no conflict (i.e., $\mathrm{K}=1$ in Dempster's rule; see n. 8), the combined $\mathbf{m}$-value for the entire frame $\{a o, \sim a o\}$ is equal to the product of the $\mathbf{m}$-values for the frame from each item of evidence, that is,

$$
\begin{gathered}
\mathbf{m}_{\mathrm{AO}}(\{a o, \sim a o\})=\mathbf{m}_{\mathrm{IO}}(\{a o, \sim a o\}) \mathbf{m}_{\mathrm{PO}}(\{a o, \sim a o\}) \mathbf{m}_{\mathrm{CO}}(\{a o, \sim a o\}) \mathbf{m}_{\mathrm{DO}}(\{a o, \sim a o\}) \\
=\mathrm{IR}_{\mathrm{AO}} \mathrm{APR}_{\mathrm{AO}} \mathrm{CR}_{\mathrm{AO}} \mathrm{DR}_{\mathrm{AO}} .
\end{gathered}
$$

Let us define a new term, $\mathrm{AR}_{\mathrm{AO}}$, for convenience as:

$$
\mathrm{AR}_{\mathrm{AO}}=\mathrm{IR}_{\mathrm{AO}} \mathrm{APR}_{\mathrm{AO}} \mathrm{CR}_{\mathrm{AO}} \mathrm{DR}_{\mathrm{AO}}
$$


From (14)-(16) and the definition of $\mathbf{m}$ function, we obtain:

$$
\begin{aligned}
\mathbf{m}_{\mathrm{AO}}(a o) & =1-\mathbf{m}_{\mathrm{AO}}(\sim a o)-\mathbf{m}_{\mathrm{AO}}(\{a o, \sim a o\}) \\
& =1-\mathrm{AR}_{\mathrm{AO}} .
\end{aligned}
$$

The corresponding belief and plausibility functions are (from equations [4] and [5]):

$$
\begin{gathered}
\mathbf{B e l}_{\mathrm{AO}}(a o)=1-\mathrm{AR}_{\mathrm{AO}} \\
\mathbf{B e l}_{\mathrm{AO}}(\sim a o)=0, \text { and } \mathbf{B e l}_{\mathrm{AO}}(\{a o, \sim a o\})=1 \\
\mathbf{P L}_{\mathrm{AO}}(a o)=1
\end{gathered}
$$

and

$$
\mathbf{P L}_{\mathrm{AO}}(\sim a o)=\mathrm{AR}_{\mathrm{AO}}
$$

Thus, $\mathrm{AR}_{\mathrm{AO}}$ is the total plausibility for $\sim a o$ at the audit objective level.

It is interesting to note from (16) and (18) that the total plausibility at the audit objective level for $\sim a o$ is the product of the individual plausibilities for $\sim a o$ (see table 2 ). As discussed

earlier in section III, plausibility is one interpretation of audit risk. So (18) along with (16) represents the audit risk model at the audit objective level without considering any other evidence at the account level or the financial statement level. This formula is similar to that of SAS No. 47. However, it is incomplete as an overall model for the audit risk because it does not include evidence at the other levels.

In the remainder of this article, we develop analytical formulas for the overall plausibility of material misstatement in the financial statement and the account and compare and contrast them with the SAS No. 47 formula. Since we have now determined the m-values directly defined at each node of figure 1, we can use the results of appendix A to derive our formulas (see appendix B for details).

\section{Audit-risk Formulas in the Belief-function Framework}

In this section, we give formulas for the overall plausibility of material misstatement at various levels of the financial statement. These formulas have been derived in appendix B. 
Total Audit Risk (Plausibility of Material Misstatement) at the Financial Statement Level

We have the following expression for total plausibility of material misstatement at the financial statement level (B-7) :

$$
\mathbf{P L}_{\mathrm{F}}^{\mathrm{t}}(\sim f)=\mathrm{AR}_{\mathrm{F}}^{\mathrm{t}}=\operatorname{IR}_{\mathrm{F}} \mathrm{APR}_{\mathrm{F}}\left[1-\prod_{\mathrm{A}}\left(1-\mathrm{AR}_{\mathrm{A}}\right)\right]
$$

where $\mathrm{AR}_{\mathrm{A}}$ and $\mathrm{AR}_{\mathrm{AO}}$ are defined in (B-4) and (16), respectively, as:

and

$$
\mathrm{AR}_{\mathrm{A}}=\mathrm{IR}_{\mathrm{A}} \mathrm{APR}_{\mathrm{A}}\left[1-\prod_{\mathrm{O}}\left(1-\mathrm{AR}_{\mathrm{AO}}\right)\right]
$$

$$
\mathrm{AR}_{\mathrm{AO}}=\mathrm{IR}_{\mathrm{AO}} \mathrm{APR}_{\mathrm{AO}} \mathrm{CR} \mathrm{AO}_{\mathrm{AR}} \mathrm{DR}_{\mathrm{AO}}
$$

Also, the total belief that the financial statement is fairly presented is given by (B-7):

$$
\operatorname{Bel}_{\mathrm{F}}^{\mathrm{t}}(f)=1-\operatorname{IR}_{\mathrm{F}} \mathrm{APR}_{\mathrm{F}}\left[1-\prod_{\mathrm{A}}\left(1-\mathrm{AR}_{\mathrm{A}}\right)\right] .
$$

Equation (19) represents total plausibility of material misstatement in the financial statement or total audit risk, $\mathrm{AR}_{\mathrm{F}}^{\mathrm{t}}$, at the financial statement level. The total belief that the financial statement is not materially misstated is given by (22). It should be noted that the algebraic form of (19) is very different from the formula discussed in SAS No. 47 or the Bayesian model. Unlike the audit risk model of SAS No. 47 or the Bayesian model, equation (19) takes into consideration all the evidence at all the levels of the financial statement. It also differs from SAS No. 47, of course, in the interpretation. Here, we interpret audit risk as a plausibility, not as a probability.

\section{Total Audit Risk (Plausibility of Material Misstatement) at the Account Level}

From (B-11), we have the following expression for total plausibility of material misstatement at the account level:

$$
\mathbf{P L}_{\mathrm{A}}^{\mathrm{t}}(\sim a)=\mathrm{AR}_{\mathrm{A}}^{\mathrm{t}}=\operatorname{IR}_{\mathrm{F}} \mathrm{APR}_{\mathrm{F}} \operatorname{IR}_{\mathrm{A}} \mathrm{APR}_{\mathrm{A}}\left[1-\prod_{\mathrm{O}}\left(1-\mathrm{AR}_{\mathrm{AO}}\right)\right]
$$

and the total belief that account ' $\mathrm{A}$ ' is not materially misstated as:

$$
\operatorname{Bel}_{\mathrm{A}}^{\mathrm{t}}(a)=1-\mathrm{AR}_{\mathrm{A}}^{\mathrm{t}}=1-\operatorname{IR}_{\mathrm{F}} \mathrm{APR}_{\mathrm{F}} \operatorname{IR}_{\mathrm{A}} \mathrm{APR}_{\mathrm{A}}\left[1-\prod_{\mathrm{O}}\left(1-\mathrm{AR}_{\mathrm{AO}}\right)\right]
$$


Here, equation (23) represents total plausibility of material misstatement or total audit risk, $\mathrm{AR}_{\mathrm{A}}^{\mathrm{t}}$, at the account level. The total belief or assurance that the account is not materially misstated is given by (24). It is again the result of aggregating all the evidence at the account level, whether the evidence is coming from the audit objective level, the financial statement level, or directly bearing on the account. It again differs from the Bayesian or SAS No. 47 formula. In (23), we find that $\mathrm{AR}_{\mathrm{A}}^{\mathrm{t}}$ is the product of three types of plausibilities: (1) plausibility arising from inherent factors (i.e., the inherent risk, $\operatorname{IR}_{\mathrm{F}} \mathrm{IR}_{\mathrm{A}}$ ), (2) plausibility arising from analytical procedures (i.e., the analytical procedure risk, $\mathrm{APR}_{\mathrm{F}} \mathrm{APR}_{\mathrm{A}}$ ), and (3) plausibility arising from the evidence at the audit objective level for the account (i.e., the combined audit risk, $\left.\left[1-\Pi_{O}\left(1-A_{A O}\right)\right]\right)$. The third term represents 1 minus the level of support obtained from the procedures performed at the audit objective level. If no procedures are performed at that level, which means $\mathrm{AR}_{\mathrm{AO}}=1$, then the support is zero and the third term equals 1 . We will give a numerical example later.

\section{Total Audit Risk (Plausibility of Material Misstatement) at the Audit Objective Level}

The total plausibility of material misstatement and total belief at the audit objective level are given by (B-15) and (B-17):

$$
\begin{gathered}
\operatorname{PL}_{\mathrm{AO}}^{\mathrm{t}}(\sim a o)=\mathrm{AR}_{\mathrm{AO}}^{\mathrm{t}}=\mathrm{IR}_{\mathrm{F}} \mathrm{APR}_{\mathrm{F}} \mathrm{IR}_{\mathrm{A}} \mathrm{APR}_{\mathrm{A}} \mathrm{AR}_{\mathrm{AO}} ; \\
\text { Bel }_{\mathrm{AO}}^{\mathrm{t}}(a o)=1-\mathrm{IR}_{\mathrm{F}} \mathrm{APR}_{\mathrm{F}} \mathrm{IR}_{\mathrm{A}} \mathrm{APR}_{\mathrm{A}} \mathrm{AR}_{\mathrm{AO}}
\end{gathered}
$$

Equation (25) represents the total plausibility that the audit objective 'AO' will not be met when all the evidence at various levels has been aggregated. The total belief that the objective will be met is given by (26). As seen in (25), the total risk at the audit objective level is the product of three terms, $\left(\mathrm{IR}_{\mathrm{F}} \mathrm{APR} \mathrm{F}_{\mathrm{F}}\right),\left(\mathrm{IR}_{\mathrm{A}} \mathrm{APR} \mathrm{A}_{\mathrm{A}}\right)$, and $\left(\mathrm{IR}_{\mathrm{AO}} \mathrm{APR} \mathrm{AO}_{\mathrm{AO}} \mathrm{CR}_{\mathrm{AO}} \mathrm{DR}_{\mathrm{AO}}\right)$, each defined at different levels. This formula resembles the multiplicative formula of SAS No. 47 if we separate the risks associated with inherent factors and analytical procedures:

$$
\mathrm{AR}_{\mathrm{AO}}^{\mathrm{t}}=\left(\mathrm{IR}_{\mathrm{F}} \mathrm{IR}_{\mathrm{A}} \mathrm{IR}_{\mathrm{AO}}\right)\left(\mathrm{APR}_{\mathrm{F}} \mathrm{APR}_{\mathrm{A}} \mathrm{APR}_{\mathrm{AO}}\right)\left(\mathrm{CR}_{\mathrm{AO}} \mathrm{DR}_{\mathrm{AO}}\right)
$$

The first factor in (27) determines the overall risk associated with inherent factors. Similarly, the second term represents the overall risk associated with analytical procedures performed at all 
levels. The third term is the product of control risk and detection risk. We must repeat that, although (27) is similar to the SAS No. 47 model, our interpretation of the risk is very different.

\section{Numerical Example}

Suppose we have only five accounts on the balance sheet and each account has five objectives. Suppose the auditor has gathered and evaluated all the relevant inherent factors at the level of the financial statement and the account and has assigned the following values for the respective plausibilities of material misstatement or risks: $\mathrm{IR}_{\mathrm{F}}=0.7$ and $\mathrm{IR}_{\mathrm{A}}=0.6$ for all the accounts. Also assume that the auditor has performed analytical procedures for various accounts and assigned a plausibility of material misstatement or risk of 0.4 to these procedures, but has not performed any analytical procedures at the financial statement level. Thus, $\mathrm{APR}_{\mathrm{A}}=0.4$ for all the accounts and $\mathrm{APR}_{\mathrm{F}}=1$. These values result in a total plausibility of error or risk at the financial statement level of 0.52 , that is, $\mathrm{AR}_{\mathrm{F}}^{\mathrm{t}}=0.52$ (table 3). This implies that, on the basis of evidence accumulated at the financial statement level and the account level, the auditor finds that the financial statement is not materially misstated with a belief or assurance of 0.48 . This information would help the auditor plan a more efficient audit than is possible with the SAS No. 47 approach. 


\section{INPUT RISKS:}

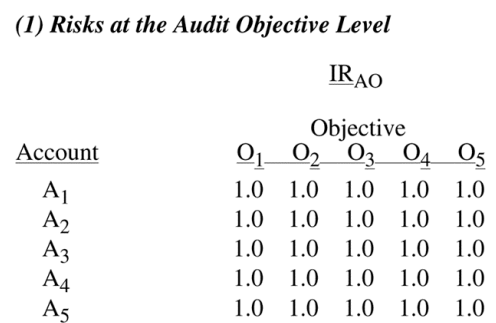

(2) Risks at the Account Level

\begin{tabular}{ccccc}
\multicolumn{6}{c}{$\underline{\mathrm{APR}}_{\mathrm{AO}}$} \\
$\underline{\mathrm{O}}_{1}$ & \multicolumn{3}{c}{ Objective } \\
1.0 & 1.0 & 1.0 & 1.0 & 1.0 \\
1.0 & 1.0 & 1.0 & 1.0 & 1.0 \\
1.0 & 1.0 & 1.0 & 1.0 & 1.0 \\
1.0 & 1.0 & 1.0 & 1.0 & 1.0 \\
1.0 & 1.0 & 1.0 & 1.0 & 1.0
\end{tabular}

$\begin{array}{cc}\text { Account } & \underline{I R_{A}} \\ \mathrm{~A}_{1} & 0.6 \\ \mathrm{~A}_{2} & 0.6 \\ \mathrm{~A}_{3} & 0.6 \\ \mathrm{~A}_{4} & 0.6 \\ \mathrm{~A}_{5} & 0.6\end{array}$

$\begin{array}{lr}\underline{\mathrm{IR}}_{\mathrm{A}} & \underline{\mathrm{APR}} \\ 0.6 & 0.4 \\ 0.6 & 0.4 \\ 0.6 & 0.4 \\ 0.6 & 0.4 \\ 0.6 & 0.4\end{array}$

\section{OUTPUT RISKS:}

Account
$\mathrm{A}_{1}$
$\mathrm{~A}_{2}$
$\mathrm{~A}_{3}$
$\mathrm{~A}_{4}$
$\mathrm{~A}_{5}$

\section{(1)}

\begin{tabular}{ccccc}
\multicolumn{5}{c}{ Total Risk at the Audit } \\
Objective Level $\left(\mathrm{AR}_{\mathrm{AO}}^{\mathrm{t}}\right)$ \\
$\underline{\mathrm{O}}_{1}-\underline{\mathrm{O}}_{2}$ & $\mathrm{O}_{3}$ & $\mathrm{O}_{4}$ & $\mathrm{O}_{5}$ \\
0.168 & 0.168 & 0.168 & 0.168 & 0.168 \\
0.168 & 0.168 & 0.168 & 0.168 & 0.168 \\
0.168 & 0.168 & 0.168 & 0.168 & 0.168 \\
0.168 & 0.168 & 0.168 & 0.168 & 0.168 \\
0.168 & 0.168 & 0.168 & 0.168 & 0.168
\end{tabular}

(2)

Total Risk at the
Account Level $\left(\mathrm{AR}_{\mathrm{A}}^{\mathrm{t}}\right)$
(From equation [23])

0.168
0.168
0.168
0.168
0.168

(3)

Total Risk and Belief at the Financial Statement Level (From equation [19])

$\mathrm{AR}_{\mathrm{F}}^{\mathrm{t}}=0.52$

$\operatorname{Bel}_{\mathrm{F}}^{\mathrm{t}}(f)=0.48$

Note: The term "risk" is used for plausibility of material misstatement. The symbols used in the table are defined in table 1.

Let us now assume that the auditor plans to proceed to the detailed level and considers the following steps: (1) collect and evaluate inherent factors at the audit objective level, (2) perform analytical procedures at the audit objective level if appropriate, (3) study and evaluate client's accounting systems and control procedures and perform test of transactions, and (4) perform direct test of balance. The results of the auditor's judgment are shown in terms of plausibilities of material misstatement or risks as inputs in tables 4-7. 


\section{INPUT RISKS:}

(1) Risks at the Audit Objective Level

\begin{tabular}{|c|c|c|c|c|c|c|c|c|c|c|c|c|c|c|c|c|c|c|c|c|}
\hline \multirow[b]{2}{*}{ Account } & \multicolumn{5}{|c|}{$\underline{\mathrm{IR}}_{\mathrm{AO}}$} & \multicolumn{5}{|c|}{$\underline{\mathrm{APR}}_{\mathrm{AO}}$} & \multicolumn{5}{|c|}{$\underline{\mathrm{CR}}_{\mathrm{AO}}$} & \multicolumn{5}{|c|}{$\underline{\mathrm{DR}}_{\mathrm{AO}}$} \\
\hline & $\underline{\mathrm{O}}_{1}$ & $\begin{array}{c}\mathrm{Ob} \\
\mathrm{O}_{2}\end{array}$ & $\begin{array}{c}\text { jecti } \\
\mathrm{O}_{3}\end{array}$ & $\mathrm{O}_{4}$ & $\mathrm{O}_{\underline{5}}$ & $\underline{\mathrm{O}}_{1}$ & $\begin{array}{c}\mathrm{O} \\
\mathrm{O}_{2}\end{array}$ & $\begin{array}{c}\text { bjecti } \\
\mathrm{O}_{3}\end{array}$ & $\mathrm{O}_{4}$ & $\mathrm{O}_{\underline{5}}$ & $\underline{\mathrm{O}}_{1}$ & $\begin{array}{c}\mathrm{O} \\
\mathrm{O}_{2}\end{array}$ & $\begin{array}{c}\text { ojecti } \\
\mathrm{O}_{3}\end{array}$ & $\mathrm{O}_{4}$ & $\mathrm{O}_{\underline{5}}$ & $\underline{\mathrm{O}}_{1}$ & $\begin{array}{c}\mathrm{Ol} \\
\mathrm{O}_{2}\end{array}$ & $\begin{array}{c}\text { jecti } \\
\mathrm{O}_{3}\end{array}$ & $\mathrm{O}_{4}$ & $\mathrm{O}_{\underline{5}}$ \\
\hline $\mathrm{A}_{1}$ & $0 . \overline{7}$ & $0 . \overline{7}$ & $0 . \overline{7}$ & 0.7 & $0 . \overline{7}$ & 1.0 & $1 . \overline{0}$ & 1.0 & 1.0 & 1.0 & 1.0 & 1.0 & 1.0 & 1.0 & 1.0 & $1 . \overline{0}$ & 1.0 & 1.0 & 1.0 & 1.0 \\
\hline $\mathrm{A}_{2}$ & 0.7 & 0.7 & 0.7 & 0.7 & 0.7 & 1.0 & 1.0 & 1.0 & 1.0 & 1.0 & 1.0 & 1.0 & 1.0 & 1.0 & 1.0 & 1.0 & 1.0 & 1.0 & 1.0 & 1.0 \\
\hline $\mathrm{A}_{3}$ & 0.7 & 0.7 & 0.7 & 0.7 & 0.7 & 1.0 & 1.0 & 1.0 & 1.0 & 1.0 & 1.0 & 1.0 & 1.0 & 1.0 & 1.0 & 1.0 & 1.0 & 1.0 & 1.0 & 1.0 \\
\hline $\mathrm{A}_{4}$ & 0.7 & 0.7 & 0.7 & 0.7 & 0.7 & 1.0 & 1.0 & 1.0 & 1.0 & 1.0 & 1.0 & 1.0 & 1.0 & 1.0 & 1.0 & 1.0 & 1.0 & 1.0 & 1.0 & 1.0 \\
\hline $\mathrm{A}_{5}$ & 0.7 & 0.7 & 0.7 & 0.7 & 0.7 & 1.0 & 1.0 & 1.0 & 1.0 & 1.0 & 1.0 & 1.0 & 1.0 & 1.0 & 1.0 & 1.0 & 1.0 & 1.0 & 1.0 & 1.0 \\
\hline
\end{tabular}

(2) Risks at the Account Level

$\begin{array}{cc}\text { Account } & \underline{\mathrm{IR}} \mathrm{A} \\ \mathrm{A}_{1} & 0.6 \\ \mathrm{~A}_{2} & 0.6 \\ \mathrm{~A}_{3} & 0.6 \\ \mathrm{~A}_{4} & 0.6 \\ \mathrm{~A}_{5} & 0.6\end{array}$

(3) Risks at the Financial Statement Level

$$
\begin{aligned}
& \mathrm{IR}_{\mathrm{F}}=0.7 \\
& \mathrm{APR}_{\mathrm{F}}=1.0
\end{aligned}
$$

\begin{tabular}{|c|c|c|c|c|c|}
\hline \multirow[b]{2}{*}{ Account } & \multicolumn{5}{|c|}{$\begin{array}{l}\text { Total Risk at the Audit } \\
\text { Objective Level }\left(\mathrm{AR}_{\mathrm{AO}}^{\mathrm{t}}\right) \\
\text { (From equation [25]) }\end{array}$} \\
\hline & $\underline{\mathrm{O}}_{1}$ & $\mathrm{O}_{2}$ & $\mathrm{O}_{3}$ & $\mathrm{O}_{4}$ & $\mathrm{O}_{5}$ \\
\hline$A_{1}$ & 0.118 & 0.118 & 0.118 & 0.118 & 0.118 \\
\hline $\mathrm{A}_{2}$ & 0.118 & 0.118 & 0.118 & 0.118 & 0.118 \\
\hline $\mathrm{A}_{3}$ & 0.118 & 0.118 & 0.118 & 0.118 & 0.118 \\
\hline $\mathrm{A}_{4}$ & 0.118 & 0.118 & 0.118 & 0.118 & 0.118 \\
\hline $\mathrm{A}_{5}$ & 0.118 & 0.118 & 0.118 & 0.118 & 0.118 \\
\hline
\end{tabular}

\section{OUTPUT RISKS:}

(2)

Total Risk at the Account Level $\left(\mathrm{AR}_{\mathrm{A}}^{\mathrm{t}}\right)$ (From equation [23])

0.168

0.168

0.168

0.168

0.168
(3)

Total Risk and Belief at the Financial Statement Level (From equation [19])

$\mathrm{AR}_{\mathrm{F}}^{\mathrm{t}}=0.52$

$\operatorname{Bel}_{\mathrm{F}}^{\mathrm{t}}(f)=0.48$

Note: The term "risk" is used for plausibility of material misstatement. The symbols used in the table are defined in table 1.

In table 4, we see that there is almost no impact of inherent factors at the audit objective level on $\mathrm{AR}_{\mathrm{F}}^{\mathrm{t}}$ and $\mathrm{AR}_{\mathrm{A}}^{\mathrm{t}}$. However, $\mathrm{AR}_{\mathrm{AO}}^{\mathrm{t}}$ reduces from 16.8 percent to 11.8 percent.

Consideration of analytical procedures at the audit objective level reduces $\mathrm{AR}_{\mathrm{F}}^{\mathrm{t}}$ to 50 percent, $\mathrm{AR}_{\mathrm{A}}^{\mathrm{t}}$ to 15.7 percent, and $\mathrm{AR}_{\mathrm{AO}}^{\mathrm{t}}$ to 7.1 percent, as shown in table 5. When accounting systems and control procedures are included in the model, the total plausibility of material misstatement (i.e., the total risk at various levels) is further reduced. $\mathrm{AR}_{\mathrm{F}}^{\mathrm{t}}=28$ percent, $\mathrm{AR}_{\mathrm{A}}^{\mathrm{t}}$ varies between 6 and 10.1 percent, and $\mathrm{AR}_{\mathrm{AO}}^{\mathrm{t}}$ between 1.4 and 2.8 percent (see table 6). 
Table 5

Audit Risk Model in Belief-Function Framework with $\mathrm{IR}_{\mathrm{AO}}, \mathrm{APR}_{\mathrm{AO}}, \mathrm{IR}_{\mathrm{A}}, \mathrm{APR}_{\mathrm{A}}$, and $\mathrm{IR}_{\mathrm{F}}$ as Inputs

INPUT RISKS:

(1) Risks at the Audit Objective Level

\begin{tabular}{cccccc} 
& \multicolumn{6}{c}{$\underline{\mathrm{IR}}_{\mathrm{AO}}$} \\
& \multicolumn{5}{c}{ Objective } \\
Account & $\underline{\mathrm{O}}_{1}$ & $\mathrm{O}_{2}$ & $\mathrm{O}_{3}$ & $\mathrm{O}_{4}$ & $\mathrm{O}_{5}$ \\
$\mathrm{~A}_{1}$ & 0.7 & 0.7 & 0.7 & 0.7 & 0.7 \\
$\mathrm{~A}_{2}$ & 0.7 & 0.7 & 0.7 & 0.7 & 0.7 \\
$\mathrm{~A}_{3}$ & 0.7 & 0.7 & 0.7 & 0.7 & 0.7 \\
$\mathrm{~A}_{4}$ & 0.7 & 0.7 & 0.7 & 0.7 & 0.7 \\
$\mathrm{~A}_{5}$ & 0.7 & 0.7 & 0.7 & 0.7 & 0.7
\end{tabular}

\begin{tabular}{ccccc}
\multicolumn{6}{c}{$\underline{\mathrm{APR}}_{\mathrm{AO}}$} \\
$\underline{\mathrm{O}}_{1}$ & $\mathrm{O}_{2}$ & $\mathrm{O}_{3}$ & $\mathrm{O}_{4}$ & $\mathrm{O}_{\underline{5}}$ \\
0.6 & 0.6 & 0.6 & 0.6 & 0.6 \\
0.6 & 0.6 & 0.6 & 0.6 & 0.6 \\
0.6 & 0.6 & 0.6 & 0.6 & 0.6 \\
0.6 & 0.6 & 0.6 & 0.6 & 0.6 \\
0.6 & 0.6 & 0.6 & 0.6 & 0.6
\end{tabular}

\begin{tabular}{ccccc}
\multicolumn{6}{c}{$\underline{\mathrm{CR}}_{\mathrm{AO}}$} \\
$\underline{\mathrm{O}}_{1}$ & $\mathrm{O}_{2}$ & $\mathrm{O}_{\underline{3}}$ & $\mathrm{O}_{4}$ & $\mathrm{O}_{\underline{5}}$ \\
1.0 & 1.0 & 1.0 & 1.0 & 1.0 \\
1.0 & 1.0 & 1.0 & 1.0 & 1.0 \\
1.0 & 1.0 & 1.0 & 1.0 & 1.0 \\
1.0 & 1.0 & 1.0 & 1.0 & 1.0 \\
1.0 & 1.0 & 1.0 & 1.0 & 1.0
\end{tabular}

$\underline{\mathrm{DR}}_{\mathrm{AO}}$

\begin{tabular}{ccccc}
\multicolumn{5}{c}{ Objective } \\
$\underline{\mathrm{O}}_{1}$ & $\mathrm{O}_{2}$ & $\mathrm{O}_{\underline{3}}$ & $\mathrm{O}_{4}$ & $\mathrm{O}_{\underline{5}}$ \\
1.0 & 1.0 & 1.0 & 1.0 & 1.0 \\
1.0 & 1.0 & 1.0 & 1.0 & 1.0 \\
1.0 & 1.0 & 1.0 & 1.0 & 1.0 \\
1.0 & 1.0 & 1.0 & 1.0 & 1.0 \\
1.0 & 1.0 & 1.0 & 1.0 & 1.0
\end{tabular}

(2) Risks at the Account Level

(3) Risks at the Financial Statement Level

$\begin{array}{cl}\text { Account } & \underline{\mathrm{IR}_{\mathrm{A}}} \\ \mathrm{A}_{1} & 0.6 \\ \mathrm{~A}_{2} & 0.6 \\ \mathrm{~A}_{3} & 0.6 \\ \mathrm{~A}_{4} & 0.6 \\ \mathrm{~A}_{5} & 0.6\end{array}$

\begin{tabular}{l||}
$\mathrm{APR}_{\mathrm{A}}$ \\
0.4 \\
0.4 \\
0.4 \\
0.4 \\
0.4
\end{tabular}

$$
\begin{aligned}
& \mathrm{IR}_{\mathrm{F}}=0.7 \\
& \mathrm{APR}_{\mathrm{F}}=1.0
\end{aligned}
$$

\begin{tabular}{|c|c|c|c|c|c|}
\hline \multirow[b]{2}{*}{ Account } & \multicolumn{5}{|c|}{$\begin{array}{l}\text { Total Risk at the Audit } \\
\text { Objective Level }\left(\mathrm{AR}_{\mathrm{AO}}^{\mathrm{t}}\right) \\
\text { (From equation [25]) }\end{array}$} \\
\hline & $\underline{\mathrm{O}}_{1}$ & $\mathrm{O}_{2}$ & $\mathrm{O}_{3}$ & $\mathrm{O}_{4}$ & $\mathrm{O}_{5}$ \\
\hline $\mathrm{A}_{1}$ & 0.071 & 0.071 & 0.071 & 0.071 & 0.071 \\
\hline $\mathrm{A}_{2}$ & 0.071 & 0.071 & 0.071 & 0.071 & 0.071 \\
\hline $\mathrm{A}_{3}$ & 0.071 & 0.071 & 0.071 & 0.071 & 0.071 \\
\hline $\mathrm{A}_{4}$ & 0.071 & 0.071 & 0.071 & 0.071 & 0.071 \\
\hline $\mathrm{A}_{5}$ & 0.071 & 0.071 & 0.071 & 0.071 & 0.071 \\
\hline
\end{tabular}

\section{OUTPUT RISKS:}

(2)

Total Risk at the Account Level $\left(\mathrm{AR}_{\mathrm{A}}^{\mathrm{t}}\right)$ (From equation [23])

0.157

0.157

0.157

0.157

0.157
(3)

Total Risk and Belief at the Financial Statement Level (From equation [19])

$\mathrm{AR}_{\mathrm{F}}^{\mathrm{t}}=0.50$

Bel $_{\mathrm{F}}^{\mathrm{t}}(f)=0.50$

Note: The term "risk" is used for plausibility of material misstatement. The symbols used in the table are defined in table 1. 
Table 6

Audit Risk Model in Belief-Function Framework with $\mathrm{IR}_{\mathrm{AO}}, \mathrm{APR}_{\mathrm{AO}}, \mathrm{CR}_{\mathrm{AO}}, \mathrm{IR}_{\mathrm{A}}, \mathrm{APR}_{\mathrm{A}}$, and $\mathrm{IR}_{\mathrm{F}}$ as Inputs

INPUT RISKS:

(1) Risks at the Audit Objective Level

\begin{tabular}{cccccc} 
& \multicolumn{6}{c}{$\underline{\mathrm{IR}}_{\mathrm{AO}}$} \\
& \multicolumn{5}{c}{ Objective } \\
Account & $\underline{\mathrm{O}}_{1}$ & $\mathrm{O}_{2}$ & $\mathrm{O}_{3}$ & $\mathrm{O}_{4}$ & $\mathrm{O}_{5}$ \\
$\mathrm{~A}_{1}$ & 0.7 & 0.7 & 0.7 & 0.7 & 0.7 \\
$\mathrm{~A}_{2}$ & 0.7 & 0.7 & 0.7 & 0.7 & 0.7 \\
$\mathrm{~A}_{3}$ & 0.7 & 0.7 & 0.7 & 0.7 & 0.7 \\
$\mathrm{~A}_{4}$ & 0.7 & 0.7 & 0.7 & 0.7 & 0.7 \\
$\mathrm{~A}_{5}$ & 0.7 & 0.7 & 0.7 & 0.7 & 0.7
\end{tabular}

\begin{tabular}{ccccc}
\multicolumn{6}{c}{$\underline{\mathrm{APR}}_{\mathrm{AO}}$} \\
$\underline{\mathrm{O}}_{\underline{1}}$ & $\mathrm{O}_{2}$ & $\mathrm{O}_{3}$ & $\mathrm{O}_{4}$ & $\mathrm{O}_{\underline{5}}$ \\
0.6 & 0.6 & 0.6 & 0.6 & 0.6 \\
0.6 & 0.6 & 0.6 & 0.6 & 0.6 \\
0.6 & 0.6 & 0.6 & 0.6 & 0.6 \\
0.6 & 0.6 & 0.6 & 0.6 & 0.6 \\
0.6 & 0.6 & 0.6 & 0.6 & 0.6
\end{tabular}

(2) Risks at the Account Level

\begin{tabular}{ccccccccccc}
\multicolumn{3}{c}{$\underline{\mathrm{CR}}_{\mathrm{AO}}$} & \multicolumn{4}{c}{$\underline{\mathrm{DR}}_{\mathrm{AO}}$} \\
\multicolumn{4}{c}{ Objective } \\
$\underline{\mathrm{O}}_{1}$ & $\mathrm{O}_{2}$ & $\mathrm{O}_{3}$ & $\mathrm{O}_{4}$ & $\mathrm{O}_{5}$ & & $\underline{\mathrm{O}}_{1}$ & $\mathrm{O}_{2}$ & $\mathrm{O}_{3}$ & $\mathrm{O}_{4}$ & $\mathrm{O}_{5}$ \\
0.2 & 0.2 & 0.2 & 0.2 & 0.2 & & 1.0 & 1.0 & 1.0 & 1.0 & 1.0 \\
0.2 & 0.2 & 0.2 & 0.2 & 0.2 & & 1.0 & 1.0 & 1.0 & 1.0 & 1.0 \\
0.4 & 0.4 & 0.4 & 0.4 & 0.4 & 1.0 & 1.0 & 1.0 & 1.0 & 1.0 \\
0.2 & 0.2 & 0.2 & 0.2 & 0.2 & 1.0 & 1.0 & 1.0 & 1.0 & 1.0 \\
0.2 & 0.2 & 0.2 & 0.2 & 0.2 & & 1.0 & 1.0 & 1.0 & 1.0 & 1.0
\end{tabular}

$\begin{array}{cc}\underline{\text { Account }} & \underline{\underline{I R}_{\mathrm{A}}} \\ \mathrm{A}_{1} & 0.6 \\ \mathrm{~A}_{2} & 0.6 \\ \mathrm{~A}_{3} & 0.6 \\ \mathrm{~A}_{4} & 0.6 \\ \mathrm{~A}_{5} & 0.6\end{array}$

(3) Risks at the Financial Statement Level

$\begin{array}{lr}\mathrm{R}_{\mathrm{A}} & \underline{\mathrm{APR}} \\ .6 & 0.4 \\ .6 & 0.4 \\ 6 & 0.4 \\ .6 & 0.4 \\ 6 & 0.4\end{array}$

OUTPUT RISKS:

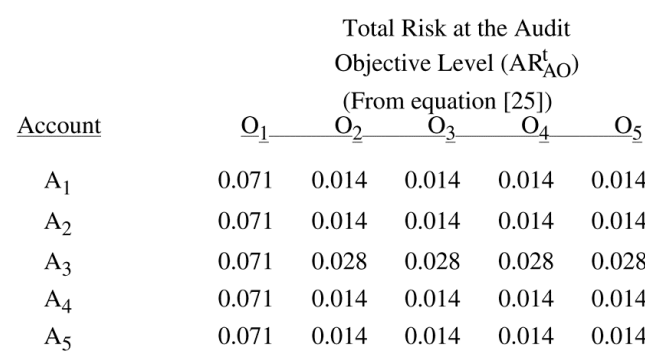

(2)

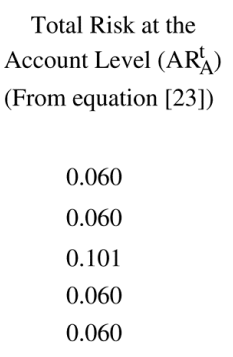

$\mathrm{IR}_{\mathrm{F}}=0.7$

$\mathrm{APR}_{\mathrm{F}}=1.0$

Note: The term "risk" is used for plausibility of material misstatement. The symbols used in the table are defined in table 1.

At this stage, the auditor decides about the extent, timing, and nature of the detailed test of balance so as to obtain the overall plausibility of material misstatement at 0.05 or an overall assurance of 0.95 . As shown in table 7, for the level of risk given in the table for each audit objective from the corresponding detailed test of balance, we obtain the desired 0.95 level of assurance or belief that the financial statement is not materially misstated (i.e., an overall plausibility or total audit risk of 0.05). The risks at the other levels vary as follows: $\mathrm{AR}_{\mathrm{A}}^{\mathrm{t}}$ varies between 1.0 and 1.4 percent, and $\mathrm{AR}_{\mathrm{AO}}^{\mathrm{t}}$ varies between 0.2 and 0.3 percent (see table 7 ). 


\section{INPUT RISKS:}

(1) Risks at the Audit Objective Level

\begin{tabular}{cccccc} 
& \multicolumn{6}{c}{$\underline{\mathrm{IR}}_{\mathrm{AO}}$} \\
& \multicolumn{5}{c}{ Objective } \\
Account & $\underline{\mathrm{O}}_{1}$ & $\mathrm{O}_{2}$ & $\mathrm{O}_{3}$ & $\mathrm{O}_{4}$ & $\mathrm{O}_{5}$ \\
$\mathrm{~A}_{1}$ & 0.7 & 0.7 & 0.7 & 0.7 & 0.7 \\
$\mathrm{~A}_{2}$ & 0.7 & 0.7 & 0.7 & 0.7 & 0.7 \\
$\mathrm{~A}_{3}$ & 0.7 & 0.7 & 0.7 & 0.7 & 0.7 \\
$\mathrm{~A}_{4}$ & 0.7 & 0.7 & 0.7 & 0.7 & 0.7 \\
$\mathrm{~A}_{5}$ & 0.7 & 0.7 & 0.7 & 0.7 & 0.7
\end{tabular}

\begin{tabular}{ccccc}
\multicolumn{6}{c}{$\underline{\mathrm{APR}}_{\mathrm{AO}}$} \\
$\underline{\mathrm{O}}_{1}$ & $\mathrm{O}_{2}$ & $\mathrm{O}_{\underline{3}}$ & $\mathrm{O}_{4}$ & $\mathrm{O}_{\underline{5}}$ \\
0.6 & 0.6 & 0.6 & 0.6 & 0.6 \\
0.6 & 0.6 & 0.6 & 0.6 & 0.6 \\
0.6 & 0.6 & 0.6 & 0.6 & 0.6 \\
0.6 & 0.6 & 0.6 & 0.6 & 0.6 \\
0.6 & 0.6 & 0.6 & 0.6 & 0.6
\end{tabular}

\begin{tabular}{ccccc}
\multicolumn{6}{c}{$\underline{\mathrm{CR}}_{\mathrm{AO}}$} \\
$\underline{\mathrm{O}}_{1}$ & \multicolumn{3}{c}{ Objective } \\
0.2 & 0.2 & 0.2 & 0.2 & 0.2 \\
0.2 & 0.2 & 0.2 & 0.2 & 0.2 \\
0.4 & 0.4 & 0.4 & 0.4 & 0.4 \\
0.2 & 0.2 & 0.2 & 0.2 & 0.2 \\
0.2 & 0.2 & 0.2 & 0.2 & 0.2
\end{tabular}

\begin{tabular}{ccccc}
\multicolumn{5}{c}{$\underline{\mathrm{DR}}_{\mathrm{AO}}$} \\
$\underline{\mathrm{O}}_{1}$ & \multicolumn{3}{c}{ Objective } \\
\hline 0.15 & 0.15 & 0.15 & 0.15 & 0.15 \\
0.15 & 0.15 & 0.15 & 0.15 & 0.15 \\
0.10 & 0.10 & 0.10 & 0.10 & 0.10 \\
0.15 & 0.15 & 0.15 & 0.15 & 0.15 \\
0.15 & 0.15 & 0.15 & 0.15 & 0.15
\end{tabular}

(2) Risks at the Account Level

(3) Risks at the Financial Statement Level

$\begin{array}{cc}\text { Account } & \underline{\mathrm{IR}_{\mathrm{A}}} \\ \mathrm{A}_{1} & 0.6 \\ \mathrm{~A}_{2} & 0.6 \\ \mathrm{~A}_{3} & 0.6 \\ \mathrm{~A}_{4} & 0.6 \\ \mathrm{~A}_{5} & 0.6\end{array}$

$$
\begin{gathered}
\mathrm{APR}_{\mathrm{A}} \\
0.4 \\
0.4 \\
0.4 \\
0.4 \\
0.4
\end{gathered}
$$

$\mathrm{IR}_{\mathrm{F}}=0.7$

$\mathrm{APR}_{\mathrm{F}}=1.0$
OUTPUT RISKS:

\begin{tabular}{|c|c|c|c|c|c|}
\hline \multirow[b]{2}{*}{ Account } & \multirow{2}{*}{\multicolumn{4}{|c|}{$\begin{array}{l}\text { Total Risk at the Audit } \\
\text { Objective Level }\left(\mathrm{AR}_{\mathrm{AO}}^{\mathrm{t}}\right) \\
\text { (From equation }[25])\end{array}$}} & \multirow[b]{2}{*}{$\mathrm{O}_{\underline{5}}$} \\
\hline & & & & & \\
\hline $\mathrm{A}_{1}$ & 0.002 & 0.002 & 0.002 & 0.002 & 0.00 \\
\hline $\mathrm{A}_{2}$ & 0.002 & 0.002 & 0.002 & 0.002 & 0.00 \\
\hline $\mathrm{A}_{3}$ & 0.003 & 0.003 & 0.003 & 0.003 & 0.00 \\
\hline $\mathrm{A}_{4}$ & 0.002 & 0.002 & 0.002 & 0.002 & 0.00 \\
\hline $\mathrm{A}_{5}$ & 0.002 & 0.002 & 0.002 & 0.002 & 0.00 \\
\hline
\end{tabular}

(2)

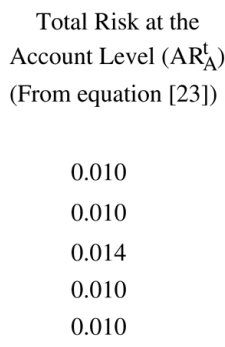

(3)

Total Risk and Belief at the Financial Statement Level

(From equation [19])

$\mathrm{AR}_{\mathrm{F}}^{\mathrm{t}}=0.05$

Bel $_{\mathrm{F}}^{\mathrm{t}}(f)=0.95$

Note: The term "risk" is used for plausibility of material misstatement. The symbols used in the table are defined in table 1.

It is important to note that consideration of the structure of evidence in our plausibility models makes the audit process more efficient. In other words, the auditor will plan less extensive tests at the audit objective level when the evidence at the financial statement level and account level is positive. One should keep in mind that certain required procedures at the detailed level must be performed; the evidence at the financial and account levels would affect only the extent of testing. As seen from table 8 , when the evidence at the account level and the financial statement level is not included in the plausibility model (as done in SAS No. 47 for the audit risk model), the total plausibility of material misstatement or the total audit risk at the financial statement level is high $\left(\mathrm{AR}_{\mathrm{F}}^{\mathrm{t}}=29\right.$ percent $)$ or the total belief that the financial statement is not materially misstated is low (0.71). Thus, without an explicit treatment of the evidence at 
the financial statement level and the account level, the auditor will always underestimate the overall assurance and will collect more evidence than necessary at the detail level.

Table 8

Audit Risk Model in Belief-Function Framework with $I R_{\mathrm{AO}}, \mathrm{APR}_{\mathrm{AO}}, \mathrm{CR}_{\mathrm{AO}}$, and $\mathrm{DR}_{\mathrm{AO}}$ as Inputs

INPUT RISKS:

(1) Risks at the Audit Objective Level

\begin{tabular}{cccccc} 
& \multicolumn{5}{c}{$\underline{\mathrm{IR}}_{\mathrm{AO}}$} \\
& \multicolumn{5}{c}{ Objective } \\
$\underline{\text { Account }}$ & $\underline{\mathrm{O}}_{1}$ & $\mathrm{O}_{2}$ & $\mathrm{O}_{3}$ & $\mathrm{O}_{4}$ & $\mathrm{O}_{5}$ \\
\hline $\mathrm{A}_{1}$ & 0.7 & 0.7 & 0.7 & 0.7 & 0.7 \\
$\mathrm{~A}_{2}$ & 0.7 & 0.7 & 0.7 & 0.7 & 0.7 \\
$\mathrm{~A}_{3}$ & 0.7 & 0.7 & 0.7 & 0.7 & 0.7 \\
$\mathrm{~A}_{4}$ & 0.7 & 0.7 & 0.7 & 0.7 & 0.7 \\
$\mathrm{~A}_{5}$ & 0.7 & 0.7 & 0.7 & 0.7 & 0.7
\end{tabular}

\begin{tabular}{|c|c|c|c|c|}
\hline \multicolumn{5}{|c|}{$\underline{\mathrm{APR}}_{\mathrm{AO}}$} \\
\hline \multicolumn{5}{|c|}{ Objective } \\
\hline 0.6 & 0.6 & 0.6 & 0.6 & 0.6 \\
\hline 0.6 & 0.6 & 0.6 & 0.6 & 0.6 \\
\hline 0.6 & 0.6 & 0.6 & 0.6 & 0.6 \\
\hline 0.6 & 0.6 & 0.6 & 0.6 & 0.6 \\
\hline 0.6 & 0.6 & 0.6 & 0.6 & 0.6 \\
\hline
\end{tabular}

\begin{tabular}{lllll}
\multicolumn{6}{c}{$\underline{\mathrm{CR}}_{\mathrm{AO}}$} \\
\multicolumn{6}{c}{ Objective } \\
$\underline{\mathrm{O}}_{1}$ & $\mathrm{O}_{2}$ & $\mathrm{O}_{3}$ & $\mathrm{O}_{4}$ & $\mathrm{O}_{5}$ \\
0.2 & 0.2 & 0.2 & 0.2 & 0.2 \\
0.2 & 0.2 & 0.2 & 0.2 & 0.2 \\
0.4 & 0.4 & 0.4 & 0.4 & 0.4 \\
0.2 & 0.2 & 0.2 & 0.2 & 0.2 \\
0.2 & 0.2 & 0.2 & 0.2 & 0.2
\end{tabular}

\begin{tabular}{ccccc}
\multicolumn{6}{c}{$\underline{\mathrm{DR}}_{\mathrm{AO}}$} \\
$\underline{\mathrm{O}}_{1}$ & \multicolumn{3}{c}{ Objective } \\
\hline 0.15 & 0.15 & 0.15 & 0.15 & 0.15 \\
0.15 & 0.15 & 0.15 & 0.15 & 0.15 \\
0.10 & 0.10 & 0.10 & 0.10 & 0.10 \\
0.15 & 0.15 & 0.15 & 0.15 & 0.15 \\
0.15 & 0.15 & 0.15 & 0.15 & 0.15
\end{tabular}

(2) Risks at the Account Level

(3) Risks at the Financial Statement Level

\begin{tabular}{cl} 
Account & $\underline{{ }_{\mathrm{IR}}}$ \\
\hline $\mathrm{A}_{1}$ & 1.0 \\
$\mathrm{~A}_{2}$ & 1.0 \\
$\mathrm{~A}_{3}$ & 1.0 \\
$\mathrm{~A}_{4}$ & 1.0 \\
$\mathrm{~A}_{5}$ & 1.0
\end{tabular}

$\underline{\mathrm{APR}}_{\mathrm{A}}$
1.0
1.0
1.0
1.0
1.0

OUTPUT RISKS:

(1)

\begin{tabular}{ccccccc} 
& \multicolumn{5}{c}{$\begin{array}{c}\text { Total Risk at the Audit } \\
\text { Objective Level }\left(\mathrm{AR}_{\mathrm{AO}}^{\mathrm{t}}\right)\end{array}$} \\
& $\underline{\mathrm{O}}_{1}$ & $\mathrm{O}_{2}$ & $\mathrm{O}_{2}$ & $\mathrm{O}_{3}$ & $\mathrm{O}_{4}$ & $\mathrm{O}_{5}$ \\
$\mathrm{~A}_{1}$ & 0.013 & 0.013 & 0.013 & 0.013 & 0.013 \\
$\mathrm{~A}_{2}$ & 0.013 & 0.013 & 0.013 & 0.013 & 0.013 \\
$\mathrm{~A}_{3}$ & 0.017 & 0.017 & 0.017 & 0.017 & 0.017 \\
$\mathrm{~A}_{4}$ & 0.013 & 0.013 & 0.013 & 0.013 & 0.013 \\
$\mathrm{~A}_{5}$ & 0.013 & 0.013 & 0.013 & 0.013 & 0.013
\end{tabular}

(2)

Total Risk at the
Account Level $\left(\mathrm{AR}_{\mathrm{A}}^{\mathrm{t}}\right)$
(From equation $[23])$
0.061
0.061
0.081
0.061
0.061

$$
\begin{aligned}
& \mathrm{IR}_{\mathrm{F}}=1.0 \\
& \mathrm{APR}_{\mathrm{F}}=1.0
\end{aligned}
$$

Note: The term "risk" is used for plausibility of material misstatement. The symbols used in the table are defined in table 1.

\section{Limitations of the Models}

We must emphasize that there are strong limitations on the applicability of the formulas we have derived, limitations that are shared by the SAS No. 47 formula and existing Bayesian formulas.

First, since we have considered only binary variables, we have distinguished only whether an account is materially misstated or not. We have not distinguished between material 
misstatement due to overstatement or understatement. This limitation will make the audit process less efficient. For example, if there are two accounts, one materially overstated and the other materially understated by the same amount, and the auditor feels that the combination of the two accounts is fairly stated because of the offsetting errors, the present approach will suggest that the combination is materially misstated and hence lead to inefficiency.

Second, we have not considered immaterial errors in individual accounts that might add up to a material error in the whole financial statement. This will also make the audit less efficient.

Third, we have assumed that each account or audit objective is equally important. This assumption may make the audit process less efficient because the auditor may still have to obtain a high level of assurance for an unimportant audit objective.

We have already mentioned other limitations due to our simplifying assumptions. We considered only a tree-type evidential structure, and only affirmative evidence is considered. As we have already explained, it may be feasible to derive formulas with these assumptions relaxed to some extent, but an algorithmic approach to the more complex case is probably preferable.

When discussing the increased efficiency possible with more accurate representation of the structure of the audit evidence, we must always bear in mind that the decrease in audit effort that is implied by plans based on such structure can decrease audit effectiveness if the inputs to the model cannot be estimated accurately by auditors who employ it. We think this gives another advantage to the belief-function approach over the Bayesian approach, since the Bayesian approach demands, in general, probability judgements that may not be available or meaningful.

\section{Conclusion}

This article has used the structure of audit evidence currently assumed in auditing standards. We have represented this structure by a network of variables; including variables that represented the financial statement as a whole, various accounts, and various audit objectives of 
each account. For simplicity, we have considered only tree-type evidential structures and only variables with two possible values.

We have used the belief-function framework to relate audit risk to plausibility of material misstatement and have derived formulas ${ }^{11}$ for the total plausibility at the three levels: financial statement level, account level, and audit objective level. The formula for the total plausibility of material misstatement at the audit objective level resembles the formula of SAS No. 47 . The total plausibility of material misstatement associated with inherent factors is the product of risks at the financial statement level, the account level, and the audit objective level. Similarly, the plausibility of error associated with analytical procedures is the product of risks at the three levels.

The formulas at the other two levels are significantly different from the SAS No. 47 model. Unlike the SAS No. 47 model or the Bayesian model, all the formulas developed in this article aggregate all the evidence obtained from procedures performed at various levels of the account.

It must be emphasized that interpretation of audit risk in this article is significantly different from the probability interpretation used in the auditing literature. For example, in the belieffunction framework, the detection risk, $\mathrm{DR}_{\mathrm{AO}}$, is the plausibility that objective 'O' of account 'A' is materially misstated, whereas the SAS No. 47 model interprets $\mathrm{DR}_{\mathrm{AO}}$ as the probability that the auditor's procedures will fail to detect material misstatements related to objective 'O' of account 'A', given that the internal control procedures have failed to prevent or detect and correct such misstatements.

The formulas derived here provide an audit planning tool that can be used to determine the level of assurance to be obtained from various sources to achieve a desired level of overall assurance or an overall plausibility of material misstatement. Unlike the SAS No. 47 formula, these formulas take into consideration all the items of evidence gathered by the auditor, whether that evidence bears on the objective level, the account level, or the financial statement level. Thus, our approach provides an improvement over the SAS No. 47 model for planning an efficient audit and evaluating the results. 
There are many other issues that need to be addressed, including (1) the level of testing needed for a desired level of support or belief, (2) the level of support or belief obtained from a given statistical result of a test procedure for different variables, (3) how to integrate belief aggregation with the cost of evidence gathering to obtain the most effective and efficient audit strategy, and (4) whether a belief-function approach to planning and evaluation of an audit is cost effective. All of these issues require further research.

\section{Footnotes}

1. With the evidential structure that we consider in this article, we obtain plausibility formulas that are closer in form to the SAS No. 47 formula than to Bayesian formulas (Leslie 1984). This is because the belief-function theory permits an auditor to have belief, say 0.6, based on the procedures performed, that a given objective is met, without having to assign the remaining 0.4 of his or her belief to whether the objective has been met or not. This unassigned belief, 0.4 , in the case, represents the plausibility that the objective is not met.

Those accustomed to Bayesian thinking may prefer to express judgments about the effectiveness of procedures in terms of conditional probabilities for detection of error, given the presence or absence of such error. In our view, such conditional probabilities are only one way of expressing intuitive judgements that may alternatively be expressed in terms of belief functions. We would express our intuitive judgments as conditional probabilities only if we intended to carry out a completely Bayesian analysis. We would express our intuitive judgments directly in terms of $\mathbf{m}$-values if we intended to carry out a belief-function analysis. It is possible, nonetheless, to express intuitive judgments in terms of conditional probabilities and then to translate these conditional probabilities into belief functions. There is some arbitrariness involved in the translation, but it can be carried out in such a way that the Bayesian approach becomes a special case of the belief-function approach (Shafer 1982). If we combine the belief function representing the conditional probabilities with a Bayesian prior using Dempster's rule, we will obtain the appropriate Bayesian posterior.

2. In general, the more accurately we model the structure of audit evidence, the more effective and efficient we can expect the audit to be. However, it is also important to recognize that if the necessary inputs to a more accurate model cannot be estimated accurately by the auditor, decreases in audit effort mandated by the model can decrease audit effectiveness.

3. Leslie et al. (1986) assume Poisson error rates, and they base their analysis on assurance factors, which represent Poisson parameters. They do not explicitly assume the independence of different items of evidence, but this assumption appears to be the justification for their practice of summing individual assurance factors to obtain an overall level.

4. We call an exhaustive and mutually exclusive set of possible answers to a question a frame. We will often use the symbol $\Theta$ to represent the frame in which we are interested. In the case of a yes-no question, the frame has only two elements; $\Theta=\{$ yes,no $\}$, or $\Theta=\{a=$ account ' $\mathrm{A}$ ' is not materially misstated, $\sim a=$ account ' $\mathrm{A}$ ' is materially misstated $\}$, etc. But, in general, a frame may be a very large set, for its question may have many possible answers. 
5. In general, if we want to make probability judgments about the elements of a frame $\Theta$ for which we have no probability measures, we can do so by relating the elements of $\Theta$ to the elements of the frame $S$ for which we have knowledge of its probability distribution. This relationship is called the compatibility relationship. The basic idea is that each probability $\mathbf{P}(s)$, where $s$ is an element of $\mathrm{S}$, should contribute to a degree of belief in the subset $\Gamma(s)$ of $\Theta$ consisting of elements with which $s$ is compatible. If several $s$ items have the same $\Gamma(s)$-in other words, $\Gamma(s)$ is equal to B for several $s$ items - then the probabilities of all these will contribute to our degree of belief that the answer to the question considered by $\Theta$ is somewhere in B. For each subset B of $\Theta$, let $\mathbf{m}(\mathrm{B})$ be the total probability for all the $\mathcal{S}$ items whose $\Gamma(s)$ is equal to B:

It follows from this formula that

$$
\mathbf{m}(\mathrm{B})=\sum_{\Gamma(\mathcal{S})=\mathrm{B}} \mathbf{P}(s) .
$$

and

$$
\sum_{\mathrm{B} \subseteq \Theta} \mathbf{m}(\mathrm{B})=1
$$

where $\varnothing$ is the empty set.

$$
\mathbf{m}(\varnothing)=0
$$

6. As a general convention, we will use capital letters to denote names of accounts or audit objectives (nodes) and small letters in script to represent their values.

7. Affirmative evidence implies that the evidence directly supports the assertion to a certain degree and provides no support for its negation. In our example, we have $\mathbf{m}_{\mathrm{PA}}(a)=0.6$, $\mathbf{m}_{\mathrm{PA}}(\sim a)=0$, and $\mathbf{m}_{\mathrm{PA}}(\{a, \sim a\})=0.4$, which implies that we have direct evidence that ' $a$ ' is met with 0.6 degree of support and no evidence that ' $a$ ' is not met.

Negative evidence implies that the evidence directly supports the negation of the assertion and provides no support for the assertion, i.e.,

$$
\mathbf{m}_{\mathrm{PA}}(a)=0, \mathbf{m}_{\mathrm{PA}}(\sim a)=0.4 \text {, and } \mathbf{m}_{\mathrm{PA}}(\{a, \sim a\})=0.6 .
$$

A mixed item of evidence can be defined as an item that provides some support for the assertion and some for its negation, i.e.,

$$
\mathbf{m}_{\mathrm{PA}}(a)=.5, \mathbf{m}_{\mathrm{PA}}(\sim a)=0.3 \text {, and } \mathbf{m}_{\mathrm{PA}}(\{a, \sim a\})=0.2 \text {. }
$$

8. Consider two independent items of evidence with $\mathbf{m}_{1}$ and $\mathbf{m}_{2}$ representing the $\mathbf{m}$-values on a frame $\Theta$. By Dempster's rule (Shafer 1976), the combined $\mathbf{m}$-value for a subset A of frame $\Theta$ is

$$
\mathbf{m}(\mathrm{A})=\mathrm{K}^{-1} \Sigma\left\{\mathbf{m}_{1}\left(\mathrm{~B}_{1}\right) \mathbf{m}_{2}\left(\mathrm{~B}_{2}\right) \mid \mathrm{B}_{1} \cap \mathrm{B}_{2}=\mathrm{A}, \mathrm{A} \neq \varnothing\right\}
$$

where $\mathrm{K}$ is the renormalization constant;

$$
\mathrm{K}=1-\Sigma\left\{\mathbf{m}_{1}\left(\mathrm{~B}_{1}\right) \mathbf{m}_{2}\left(\mathrm{~B}_{2}\right) \mid \mathrm{B}_{1} \cap \mathrm{B}_{2}=\varnothing\right\}
$$


The second term in $\mathrm{K}$ represents the conflict between the two items of evidence. If the conflict term is 1 , i.e., if the two items of evidence exactly contradict each other, then $\mathrm{K}=0$ and, in such a situation, the two items of evidence are not combinable. In other words, Dempster's rule cannot be used when $\mathrm{K}=0$.

9. Here is another example. Suppose the evidence gathered up to this point gives us the following m-values: $\mathbf{m}(a)=0.95, \mathbf{m}(\sim a)=0.02, \mathbf{m}(\{a, \sim a\})=0.03$. From Equations (4) and (5), we obtain $\operatorname{Bel}(a)=0.95, \operatorname{PL}(a)=0.98, \operatorname{Bel}(\sim a)=0.02, \operatorname{PL}(\sim a)=0.05$. This means that we have 0.95 degree of belief that ' $a$ ' is true and 0.02 degree of belief that ' $\sim a$ ' is true.

However, the plausibility of ' $\sim a$ ' is 0.05 , which means that if we had to stop at this point, we would be taking a maximum risk of 0.05 that ' $\sim a$ ' is true although the belief in ' $\sim a$ ' is only 0.02 .

10. This paper is available on request from the authors.

11. As Boritz (1990) has shown, almost identical expressions for the overall audit risk can be obtained with probability theory. 


\section{References}

American Institute of Certified Public Accountants. 1983. Statement on Auditing Standards, No, 47: Audit Risk and Materiality in Conducting an Audit. New York: AICPA.

1988a. Statement on Auditing Standards, No. 55: Consideration of the Internal Control Structure in a Financial Statement Audit. New York: AICPA.

.1988b. Statement on Auditing Standard, No. 56: Analytical Procedures. New York: AICPA.

Akresh, A. D., J. K. Loebbecke, and W. R. Scott. 1988. Audit approaches and techniques. In Research Opportunities in Auditing: The Second Decade, edited by A. R. Abdel-khalik and Ira Solomon. Sarasota, FL: AAA, 13-55.

Arens, A. A., and J. K. Loebbecke. 1988. Auditing: An Integrated Approach. Englewood Cliffs, NJ: Prentice-Hall.

Boritz, J. E. 1990. Appropriate and inappropriate approaches to combining evidence in an assertion-based auditing framework. Working Paper, School of Accountancy, University of Waterloo, Canada.

and R. E. Jensen. 1985. An hierarchical, assertion-oriented approach to planning audit evidence-gathering procedures. Presented at the Symposium on Audit Judgment and Evidence Evaluation, University of Southern California.

, and A. K. P. Wensley. 1990. Structuring the assessment of audit evidence: An expert system approach. Auditing: A Journal of Practice and Theory 9 (Supplement): 49-109.

Buchanan, B. G., and E. H. Shortliffe. 1984. Rule-Based Expert Systems: The MYCIN Experiments of the Stanford Heuristic Programming Project. Reading, MA: AddisonWesley.

Canadian Institute of Chartered Accountants. 1980. Extent of Audit Testing. Toronto, Canada: CICA.

Cushing, B. E., and J. K. Loebbecke. 1983. Analytical approaches to audit risk: A survey and analysis. Auditing: A Journal of Practice and Theory 3 (Fall): 23-41.

Graham, L. E. 1985a. Audit risk - Part I. The CPA Journal (August): 12-21. . 1985b. Audit risk - Part II. The CPA Journal (September): 34-40. .1985c. Audit risk - Part III. The CPA Journal (October): 36-43. . 1985d. Audit risk - Part IV. The CPA Journal (November): 38-45. . 1985e. Audit risk - Part V. The CPA Journal (December): 26-33.

Kinney, Jr., W. R. 1984. Discussant's response to an analysis of the audit framework focusing on inherent risk and the role of statistical sampling in compliance testing. Proceedings of the 1984 Touche Ross/University of Kansas Symposium on Auditing Problems. Lawrence, KS: School of Business, University of Kansas, 126-32. 
1989. Achieved audit risk and the audit outcome space. Auditing: A Journal of Practice and Theory 8 (Supplement): 67-97.

Leslie, D. A. 1984. An analysis of the audit framework focusing on inherent risk and the role of statistical sampling in compliance testing. Proceedings of the 1984 Touche Ross/University of Kansas Symposium on Auditing Problems. Lawrence, KS: School of Business, University of Kansas, 89-125.

, and S. J. Aldersley, D. J. Cockburn, and C. J. Reiter. 1986. An assertion-based approach to auditing (discussant's remarks). Proceedings of the 1986 Touche Ross/University of Kansas Symposium on Auditing Problems. Lawrence, KS: School of Business, University of Kansas, 31-67.

Shafer, G. 1976. A Mathematical Theory of Evidence. Princeton University Press.

1982. Belief functions and parametric models. Journal of the Royal Statistical Society, 44 (Series B): 322-52.

. 1986. Probability judgment in artificial intelligence and expert systems. Statistical Science 2 (1): 3-16.

, and P. P. Shenoy. 1988. Local computation in hypertrees. Working Paper No. 201, School of Business, University of Kansas, Lawrence, KS.

and P. P. Shenoy. 1990. Probability propagation. Annals of Mathematics and Artificial Intelligence 2 (1-4): 327-52.

, P. P. Shenoy, and R. P. Srivastava. 1988. Auditor's Assistant: A knowledge engineering tool for audit decisions. Proceedings of the 1988 Touche Ross/University of Kansas Symposium on Auditing Problems. Lawrence, KS: School of Business, University of Kansas, 61-84.

, and R. P. Srivastava. 1990. The bayesian and belief-function formalisms: A general perspective for auditing. Auditing: A Journal of Practice and Theory 9 (Supplement): 11048.

Shenoy, P.P. 1989. A valuation-based language for expert systems. International Journal of Approximate Reasoning 3 (5): 383-411.

, and G. Shafer. 1988. An axiomatic framework for bayesian and belief-function propagation. Proceedings of the Fourth Workshop on Uncertainty in Artificial Intelligence. St. Paul, MN: AAAI Press, 307-14.

and G. Shafer. 1990. Axioms for probability and belief-function propagation. In Uncertainty in Artificial Intelligence 4, edited by R. D. Shachter, et al. Amsterdam: NorthHolland, 169-98.

Zarley, D., Yen-Teh Hsia, and G. Shafer. 1988. Evidential reasoning using DELIEF. Proceedings of the Seventh National Conference on Artificial Intelligence, Vol. 1. Cambridge, MA: AAAI Press, 205-09. 


\section{Appendix A}

\section{Propagation of m-Values in an "And" Tree}

Propagation of beliefs (or $\mathbf{m}$-values) in a network is quite complex. Extensive work on this topic is reported in the artificial intelligence literature. To mention a few studies, the work by Shafer (1976, 1986), Shafer and Shenoy (1988, 1990), Shenoy and Shafer $(1988,1990)$, Zarley et al. (1988), and Shenoy (1989) is important for this purpose.

We will summarize results of propagation of beliefs in an "and" tree. These results will be useful in deriving analytical formulas in appendix B. There are two important directions for propagation for the overall aggregation of beliefs in an "and" tree. One direction is from the subobjectives to the main objective. The second direction is to propagate to a given subobjective from the main objective and the other subobjectives. The details of this work are given in a working paper that is available from the authors on request.

Propagation of $\boldsymbol{m}$-Values from Audit Objectives to the Respective Accounts

Here, we summarize the results of propagation of $\mathbf{m}$-values in an "and" tree (figure 1) from subobjectives to the main objectives, that is, from audit objectives to corresponding accounts or from accounts to the financial statement. In the case of propagation from audit objectives (AOs) to an account 'A', one obtains the following values:

$$
\begin{aligned}
\mathbf{m}_{\mathrm{A} \leftarrow \text { all } \mathrm{AO}}^{\prime}(a) & =\prod_{\mathrm{i}=1}^{\mathrm{n}} \mathbf{m}_{\mathrm{AO}_{\mathrm{i}}}\left(a o_{\mathrm{i}}\right) \\
\mathbf{m}_{\mathrm{A} \leftarrow \text { all } \mathrm{AO}}^{\prime}(\sim a) & =\sum_{\mathrm{i}=1}^{\mathrm{n}} \mathbf{m}_{\mathrm{AO}_{\mathrm{i}}}\left(\sim a o_{\mathrm{i}}\right) \prod_{\mathrm{j} \neq \mathrm{i}}^{\mathrm{n}} \mathbf{m}_{\mathrm{AO}_{\mathrm{j}}}\left(a o_{\mathrm{j}}\right) \\
& +\sum_{\mathrm{i}=1}^{\mathrm{n}} \sum_{\mathrm{j} \neq \mathrm{i}}^{\mathrm{n}} \mathbf{m}_{\mathrm{AO}_{\mathrm{i}}}\left(\sim a o_{\mathrm{i}}\right) \mathbf{m}_{\mathrm{AO}_{\mathrm{j}}}\left(\sim a o_{\mathrm{j}}\right) \prod_{\mathrm{k} \neq \mathrm{i}, \mathrm{k} \neq \mathrm{j}}^{\mathrm{n}} \mathbf{m}_{\mathrm{AO}_{\mathrm{k}}}\left(a o_{\mathrm{k}}\right) \\
& +. .+. \cdot+\prod_{\mathrm{i}=1}^{\mathrm{n}} \mathbf{m}_{\mathrm{AO}_{\mathrm{i}}}\left(\sim a o_{\mathrm{i}}\right)
\end{aligned}
$$




$$
\begin{aligned}
& +\sum_{\mathrm{i}=1}^{\mathrm{n}} \mathbf{m}_{\mathrm{AO}_{\mathrm{i}}}\left(\sim a o_{\mathrm{i}}\right) \prod_{\mathrm{j} \neq \mathrm{i}}^{\mathrm{n}} \mathbf{m}_{\mathrm{AO}_{\mathrm{j}}}\left(\left\{a o_{\mathrm{j}}, \sim a o_{\mathrm{j}}\right\}\right) \\
& +\sum_{\mathrm{i}=1}^{\mathrm{n}} \sum_{\mathrm{j} \neq \mathrm{i}}^{\mathrm{n}} \mathbf{m}_{\mathrm{AO}_{\mathrm{i}}}\left(\sim a o_{\mathrm{i}}\right) \mathbf{m}_{\mathrm{AO}_{\mathrm{j}}}\left(\sim a o_{\mathrm{j}}\right) \prod_{\mathrm{k} \neq \mathrm{i}, \mathrm{k} \neq \mathrm{j}}^{\mathrm{n}} \mathbf{m}_{\mathrm{AO}_{\mathrm{k}}}\left(\left\{a o_{\mathrm{k}}, \sim a o_{\mathrm{k}}\right\}\right)+\ldots+ \\
& +\sum_{\mathrm{j}=1}^{\mathrm{n}} \prod_{\mathrm{i} \neq \mathrm{j}}^{\mathrm{n}} \mathbf{m}_{\mathrm{AO}_{\mathrm{i}}}\left(\sim a o_{\mathrm{i}}\right) \mathbf{m}_{\mathrm{AO}_{\mathrm{j}}}\left(\left\{a o_{\mathrm{j}}, \sim a o_{\mathrm{j}}\right\}\right),
\end{aligned}
$$

and

$$
\mathbf{m}_{\mathrm{A} \leftarrow \text { all } \mathrm{AO}}^{\prime}(\{a, \sim a\})=1-\mathbf{m}_{\mathrm{A} \leftarrow \text { all } \mathrm{AO}}^{\prime}(a)-\mathbf{m}_{\mathrm{A} \leftarrow \text { all } \mathrm{AO}}^{\prime}(\sim a) .
$$

These values may look very complex but they are intuitive. For example, (A-1) represents the propagated $\mathbf{m}$-value for the state ' $a$ ' that the account ' $\mathrm{A}$ ' is not materially misstated. This value is equal to the product of all the $\mathbf{m}$-values defined at each audit objective for ' $a o^{\prime}$ that the objective is met. This result is similar to the probability rule giving the probability that the account is not materially misstated as equal to the product of the individual probabilities that the audit objectives are met provided the "and" relationship is valid.

Equation (A-2) is also intuitive. It represents the resultant $\mathbf{m}$-value for ' $\sim a$ ' received from all its audit objectives. The account is materially misstated when at least one or all of the objectives are not met. There are several situations that contribute to this condition: (1) at least one of the objectives is not met but the rest have been met, (2) all the objectives are not met, and (3) at least one of the objectives is not met but we have no knowledge whether the rest have been met or not. The first two terms in (A-2) represent the first situation. The third term represents the second situation. The last three terms in (A-2) represent the third situation.

For affirmative items of evidence (i.e., for $\mathbf{m}_{\mathrm{A}}(\sim a)=0$ and $\mathbf{m}_{\mathrm{AO}_{\mathrm{j}}}\left(\sim a o_{\mathrm{j}}\right)=0$ for all $\mathrm{j}$ ), equation (A-2) reduces to the following simple form:

$$
\mathbf{m}_{\mathrm{A} \leftarrow \text { all } \mathrm{AO}}(\sim a)=0,
$$

while (A-1) and (A-3) remain unchanged. 
Propagation of m-Values to a Given Subobjective from the Main Objective and the Other Subobjectives

In this section, we want to summarize the results of propagation to a given subobjective from the main objective and the other subobjectives. For example, the $\mathbf{m}$-values propagated to a given audit objective $\mathrm{AO}_{\mathrm{i}}$ from account ' $\mathrm{A}$ ' and the remaining audit objectives can be given by:

$$
\begin{gathered}
\mathbf{m}_{\mathrm{AO}_{\mathrm{i}} \leftarrow \text { A\&all other AO's }}^{\prime}\left(a o_{\mathrm{i}}\right)=\mathrm{K}_{\mathrm{i}}^{-1} \mathbf{m}_{\mathrm{A}}(a) \prod_{\mathrm{j} \neq \mathrm{i}}^{\mathrm{n}}\left[1-\mathbf{m}_{\mathrm{AO}_{\mathrm{j}}}\left(\sim a o_{\mathrm{j}}\right)\right], \\
\mathbf{m}_{\mathrm{AO}_{\mathrm{i}} \leftarrow \text { A\&all other AO's }}^{\prime}\left(\sim a o_{\mathrm{i}}\right)=\mathrm{K}_{\mathrm{i}}^{-1} \mathbf{m}_{\mathrm{A}}(\sim a) \prod_{\mathrm{j} \neq \mathrm{i}}^{\mathrm{n}} \mathbf{m}_{\mathrm{AO}_{\mathrm{j}}}\left(a o_{\mathrm{j}}\right), \\
\mathbf{m}_{\mathrm{AO}_{\mathrm{i}} \leftarrow \text { A\&all other AO's }}^{\prime}\left(\left\{a o_{\mathrm{i}}, \sim a o_{\mathrm{i}}\right\}\right)=1-\mathbf{m}_{\mathrm{AO}_{\mathrm{i}} \leftarrow \mathrm{A} \& \text { all other } \mathrm{AO}^{\prime} \mathrm{s}}^{\prime}\left(a o_{\mathrm{i}}\right) \\
-\mathbf{m}_{\mathrm{AO}_{\mathrm{i}} \leftarrow \text { A\&all other } \mathrm{AO}^{\prime} \mathrm{s}}^{\prime}\left(\sim a o_{\mathrm{i}}\right),
\end{gathered}
$$

where $\mathrm{K}_{\mathrm{i}}$ is the renormalization constant that can be written as $\mathrm{K}_{\mathrm{i}}=\left[1-\mathbf{m}_{\mathrm{A}}(a) \mathrm{C}_{\mathrm{i}}\right]$ and $\mathrm{C}_{\mathrm{i}}$ is given by

$$
\begin{aligned}
& \mathrm{C}_{\mathrm{i}}=\sum_{\mathrm{j} \neq \mathrm{i}}^{\mathrm{n}} \mathbf{m}_{\mathrm{AO}_{\mathrm{j}}}\left(\sim a o_{\mathrm{j}}\right) \prod_{\mathrm{k} \neq \mathrm{j}}^{\mathrm{n}} \mathbf{m}_{\mathrm{AO}_{\mathrm{k}}}\left(a o_{\mathrm{k}}\right) \\
& +\sum_{\mathrm{j} \neq \mathrm{i}}^{\mathrm{n}} \sum_{\mathrm{k} \neq \mathrm{j}}^{\mathrm{n}} \mathbf{m}_{\mathrm{AO}_{\mathrm{j}}}\left(\sim a o_{\mathrm{j}}\right) \mathbf{m}_{\mathrm{AO}_{\mathrm{k}}}\left(\sim a o_{\mathrm{k}}\right) \prod_{1 \neq \mathrm{j}, 1 \neq \mathrm{k}}^{\mathrm{n}} \mathbf{m}_{\mathrm{AO}_{\mathrm{l}}}\left(a o_{\mathrm{l}}\right) \\
& +\ldots+. .+\prod_{\mathrm{j} \neq \mathrm{i}}^{\mathrm{n}} \mathbf{m}_{\mathrm{AO}_{\mathrm{j}}}\left(\sim a o_{\mathrm{j}}\right) \\
& +\sum_{\mathrm{j} \neq \mathrm{i}}^{\mathrm{n}} \mathbf{m}_{\mathrm{AO}_{\mathrm{j}}}\left(\sim a o_{\mathrm{j}}\right) \prod_{\mathrm{k} \neq \mathrm{j}}^{\mathrm{n}} \mathbf{m}_{\mathrm{AO}_{\mathrm{k}}}\left(\left\{a o_{\mathrm{k}}, \sim a o_{\mathrm{k}}\right\}\right) \\
& +\sum_{\mathrm{j} \neq \mathrm{i}}^{\mathrm{n}} \sum_{\mathrm{k} \neq \mathrm{i}}^{\mathrm{n}} \mathbf{m}_{\mathrm{AO}_{\mathrm{j}}}\left(\sim a o_{\mathrm{j}}\right) \mathbf{m}_{\mathrm{AO}_{\mathrm{k}}}\left(\sim a o_{\mathrm{k}}\right) \prod_{1 \neq \mathrm{i}, 1 \neq \mathrm{j}}^{\mathrm{n}} \mathbf{m}_{\mathrm{AO}_{\mathrm{l}}}\left(\left\{a o_{1}, \sim a o_{1}\right\}\right)+\ldots+ \\
& +\sum_{\mathrm{j} \neq \mathrm{i}}^{\mathrm{n}} \prod_{\mathrm{k} \neq \mathrm{j}}^{\mathrm{n}} \mathbf{m}_{\mathrm{AO}_{\mathrm{k}}}\left(\sim a o_{\mathrm{k}}\right) \mathbf{m}_{\mathrm{AO}_{\mathrm{j}}}\left(\left\{a o_{\mathrm{j}}, \sim a o_{\mathrm{j}}\right\}\right)
\end{aligned}
$$

Again, the above equations may appear complex but the results are intuitive. For example, the $\mathbf{m}$-value expressed in (A-5) represents that the audit objective $\mathrm{AO}_{\mathrm{i}}$ is met if account 
'A' is not materially misstated $\left(\mathbf{m}_{\mathrm{A}}(a) \neq 0\right)$ and the other audit objectives are either met or their status is unknown $\left(\mathbf{m}_{\mathrm{AO}_{\mathrm{j}}}\left(\sim a o_{\mathrm{j}}\right)<1\right)$. Equation $(\mathrm{A}-6)$ is easier to understand. It tells us that there is finite support for the audit objective's not having been met if the account is found to be materially misstated but the other audit objectives have been met. The renormalization constant, $\mathrm{K}_{\mathrm{i}}$, in (A-5)-(A-7) represents 1 minus the conflict term. In general, the conflict term is defined as the sum of all the products of $\mathbf{m}$-values of the sets of elements whose intersection is a null set. In our case, conflict will occur when there is a finite support that the account is not materially misstated $\left(\mathbf{m}_{\mathrm{A}}(a) \neq 0\right)$ and at least one of the other audit objectives is not met $\left(\mathrm{C}_{\mathbf{i}} \neq 0\right)$.

In the case of affirmative items of evidence (i.e., $\mathbf{m}_{\mathrm{A}}(\sim a)=0$ and $\mathbf{m}_{\mathrm{AO}_{\mathrm{j}}}\left(\sim a o_{\mathrm{j}}\right)=0$ for all $\mathrm{j}$ ), which is the case assumed in the present work, the renormalization constant becomes 1 and $(\mathrm{A}-5)$ and $(\mathrm{A}-6)$ reduce to:

$$
\begin{gathered}
\mathbf{m}_{\mathrm{AO}_{\mathrm{i}} \leftarrow \mathrm{A} \& \text { all other AO's }}^{\prime}\left(a o_{\mathrm{i}}\right)=\mathbf{m}_{\mathrm{A}}(a), \\
\mathbf{m}_{\mathrm{AO}_{\mathrm{i}} \leftarrow \mathrm{A} \& \text { all other AO's }}^{\prime}\left(\sim a o_{\mathrm{i}}\right)=0,
\end{gathered}
$$

while (A-7) remains unchanged. From (A-9), we find that, in the case of affirmative items of evidence, when $\mathbf{m}$-values propagate to a given subobjective from the main objective and the other subobjectives, the $\mathbf{m}$-values received by the subobjective are not a function of the $\mathbf{m}$-values of the other subobjectives. 


\section{Appendix B}

\section{Derivation of Plausibility Formulas or Audit Risk Formulas}

In this appendix, our main objective is to derive formulas for plausibility of material misstatement (i.e., audit-risk formulas; see n. 2) within the belief-function framework for an evidential network (an "and" tree) given in figure 1. To achieve this objective, we need to aggregate all the items of evidence in figure 1. As discussed earlier, the process of combining various $\mathbf{m}$-values in a network is, in fact, a process of propagating $\mathbf{m}$-values through the network of variables. We will use the general results presented in appendix A to derive the audit risk formulas in the following sections. As mentioned earlier, the following assumptions are made in the derivation of the formulas.

First, each node (variable, such as an account or audit objective) in the tree is assumed to be a binary variable. In fact, the variables in an "and" tree are binary by definition. The general approach of aggregating evidence by using the belief-function framework is still valid for nonbinary variables, but the analytical formulas for such cases will be intractable. Second, each item of evidence is assumed to be affirmative in nature (i.e., the evidence provides positive support to the assertion and no support to its negation).

\section{Financial Statement Level}

The objective here is to derive a formula for the total plausibility of material misstatement or audit risk, at the financial statement level. This is achieved by combining all mvalues that are either defined directly at the financial statement node $(\mathrm{F})$ or have been propagated to $\mathrm{F}$ from all other nodes in the network (see figure 2 ). We will proceed with the propagation process in two steps. First, we will consider propagation from audit objectives (AO's) to an account (A) and then combine these values from the audit objectives with the $\mathbf{m}$-values at the account. Second, we propagate the resultant $\mathbf{m}$-values from various accounts to the financial statement node and combine them with the m-values at the financial statement level. This process will yield the desired audit risk (plausibility of material misstatement) formula. 
Figure 2

Propagation of m-Values from Audit Objectives and Accounts to the Financial Statement

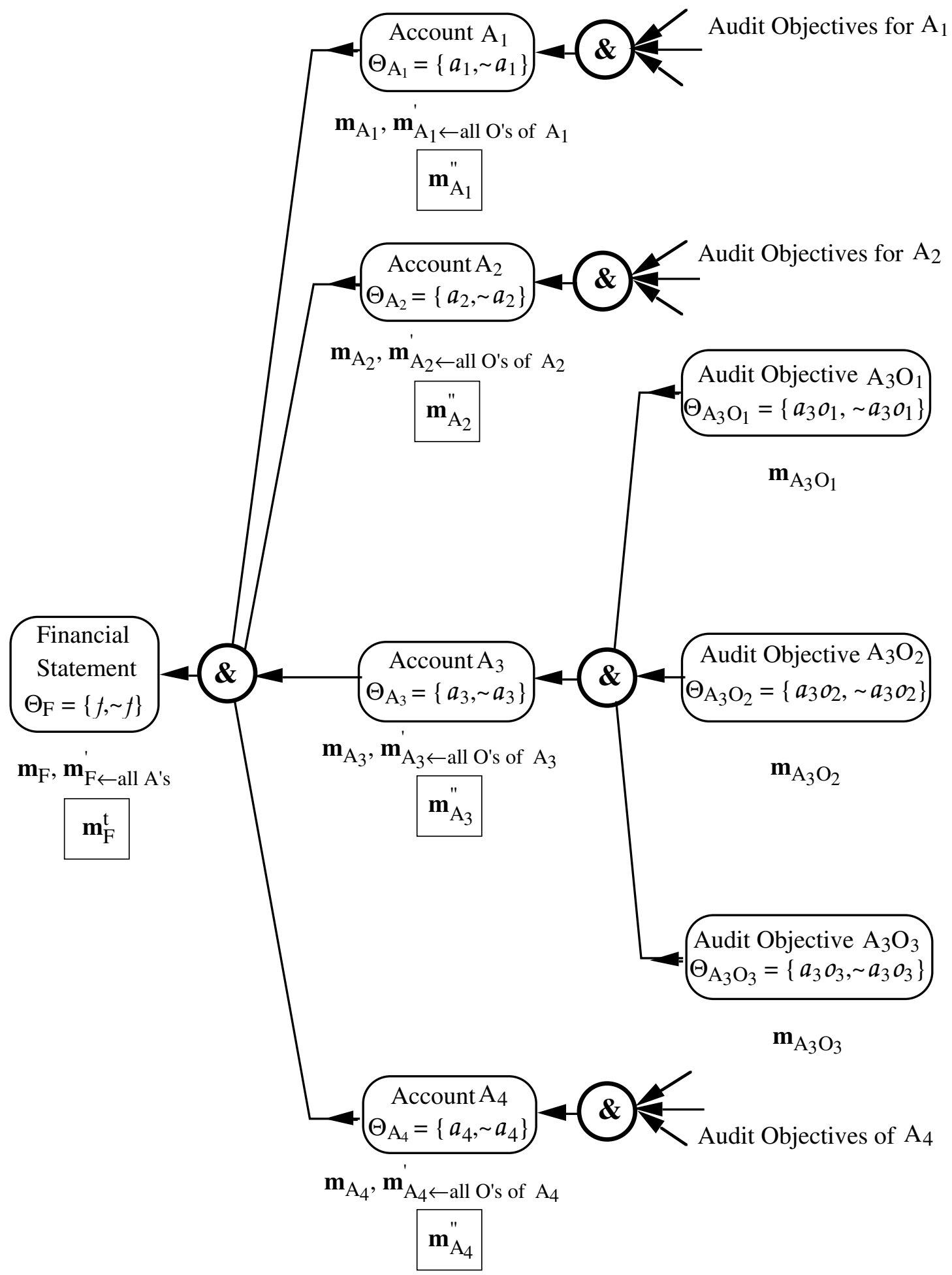


For the first step above, as an illustration, let us consider propagation of $\mathbf{m}$-values defined at the three audit objectives of account ' $\mathrm{A}_{3}$ ' in figure 2 to the account. These $\mathbf{m}$-values are the result of combining all four items of evidence at the audit objective level and are given, in general terms, in (14)-(17). When these $\mathbf{m}$-values are propagated to account $\mathrm{A}_{3}$, we obtain the following values using (A-1), (A-3), and (A-4):

$$
\begin{gathered}
\mathbf{m}_{\mathrm{A}_{3} \leftarrow \text { all O's of } \mathrm{A}_{3}}^{\prime}\left(a_{3}\right)=\prod_{\mathrm{i}=1}^{3} \mathbf{m}_{\mathrm{A}_{3} \mathrm{O}_{\mathrm{i}}}\left(a_{3} o_{\mathrm{i}}\right)=\prod_{\mathrm{i}=1}^{3}\left(1-\mathrm{AR}_{\mathrm{A}_{3} \mathrm{O}_{\mathrm{i}}}\right), \\
\mathbf{m}_{\mathrm{A}_{3} \leftarrow \text { all O's of } \mathrm{A}_{3}}^{\prime}\left(\sim a_{3}\right)=0, \\
\mathbf{m}_{\mathrm{A}_{3} \leftarrow \text { all O's of } \mathrm{A}_{3}}^{\prime}\left(\left\{a_{3} o_{\mathrm{i}}, \sim a_{3} o_{\mathrm{i}}\right\}\right)=1-\prod_{\mathrm{i}=1}^{3}\left(1-\mathrm{AR}_{\left.\mathrm{A}_{3} \mathrm{O}_{\mathrm{i}}\right),}\right.
\end{gathered}
$$

where $\mathrm{AR}_{\mathrm{AO}}$ 's are defined as in (16).

The next step is to combine the above $\mathbf{m}$-values with $\mathbf{m}_{\mathrm{A}_{3}}$ at the account, as defined in general terms in (11)-(13), before propagating it to F. Since there is no conflict in the two sets of $\mathbf{m}$-values at the account level and there also is no support for $\sim a_{3}$, the combined values when using Dempster's rule becomes:

$$
\begin{gathered}
\mathbf{m}_{\mathrm{A}_{3}}^{\prime \prime}\left(a_{3}\right)=1-\mathbf{m}_{\mathrm{A}_{3}}^{\prime \prime}\left(\left\{a_{3}, \sim a_{3}\right\}\right)=1-\operatorname{IR}_{\mathrm{A}_{3}} \mathrm{APR}_{\mathrm{A}_{3}}\left[1-\prod_{\mathrm{i}=1}^{3}\left(1-\mathrm{AR}_{\mathrm{A}_{3} \mathrm{O}_{\mathrm{i}}}\right)\right], \\
\mathbf{m}_{\mathrm{A}_{3}}^{\prime \prime}\left(\sim a_{3}\right)=0 \\
\mathbf{m}_{\mathrm{A}_{3}}^{\prime \prime}\left(\left\{a_{3}, \sim a_{3}\right\}\right)=\mathbf{m}_{\mathrm{A}_{3}}\left(\left\{a_{3}, \sim a_{3}\right\}\right) \mathbf{m}_{\mathrm{A}_{3} \leftarrow \text { all O's of } \mathrm{A}_{3}\left(\left\{a_{3}, \sim a_{3}\right\}\right)}^{\prime} \\
=\operatorname{IR}_{\mathrm{A}_{3}} \mathrm{APR}_{\mathrm{A}_{3}}\left[1-\prod_{\mathrm{i}=1}^{3}\left(1-\mathrm{AR}_{\left.\left.\mathrm{A}_{3} \mathrm{O}_{\mathrm{i}}\right)\right]}\right.\right.
\end{gathered}
$$

In general, one can write the above result for any account $\mathrm{A}$ in an "and" tree similar to that in figure 1 as:

$$
\begin{gathered}
\mathbf{m}_{\mathrm{A}}^{\prime \prime}(a)=1-\mathbf{m}_{\mathrm{A}}^{\prime \prime}(\{a, \sim a\})=1-\mathrm{IR}_{\mathrm{A}} \mathrm{APR}_{\mathrm{A}}\left[1-\prod_{\mathrm{O}}\left(1-\mathrm{AR}_{\mathrm{AO}}\right)\right], \\
\mathbf{m}_{\mathrm{A}}^{\prime \prime}(\sim a)=0, \\
\mathbf{m}_{\mathrm{A}}^{\prime \prime}(\{a, \sim a\})=\mathrm{IR}_{\mathrm{A}} \mathrm{APR}_{\mathrm{A}}\left[1-\prod_{\mathrm{O}}\left(1-\mathrm{AR}_{\mathrm{AO}}\right)\right] .
\end{gathered}
$$

Let us define a new term, $\mathrm{AR}_{\mathrm{A}}$, for simplicity as:

$$
\mathrm{AR}_{\mathrm{A}}=\mathrm{IR}_{\mathrm{A}} \mathrm{APR}_{\mathrm{A}}\left[1-\prod_{\mathrm{O}}\left(1-\mathrm{AR}_{\mathrm{AO}}\right)\right]
$$


To combine all the items of evidence at $\mathrm{F}$, we propagate the $\mathbf{m}$-values in (B-3) to $\mathrm{F}$ (see figure 2). Using (A-1), (A-3), and (A-4), we can write these values, in general form, as:

$$
\begin{gathered}
\mathbf{m}_{\mathrm{F} \leftarrow \text { all A's }}^{\prime}(f)=\underset{\mathrm{A}}{\prod_{\mathrm{A}}} \mathbf{m}_{\mathrm{A}}^{\prime \prime}(a)=\prod_{\mathrm{A}}\left(1-\mathrm{AR}_{\mathrm{A}}\right), \\
\mathbf{m}_{\mathrm{F} \leftarrow \text { all A's }}^{\prime}(\sim f)=0, \\
\mathbf{m}_{\mathrm{F} \leftarrow \text { all A's }}^{\prime}(\{f, \sim f\})=1-\underset{\mathrm{A}}{\prod_{\mathrm{A}}}\left(1-\mathrm{AR}_{\mathrm{A}}\right) .
\end{gathered}
$$

Now, to complete the process, the above $\mathbf{m}$-values are combined with $\mathbf{m}_{\mathrm{F}}$ at $\mathrm{F}$ as defined in (8)-(10). Using Dempster's rule to combine $\mathbf{m}_{\mathrm{F} \leftarrow \text { all } \mathrm{A}^{\prime} \mathrm{s}}$ in (B-5) and $\mathbf{m}_{\mathrm{F}}$, we obtain the total m-values as:

$$
\begin{gathered}
\mathbf{m}_{\mathrm{F}}^{\mathrm{t}}(f)=1-\mathbf{m}_{\mathrm{F}}^{\mathrm{t}}(\{f, \sim f\})=1-\operatorname{IR}_{\mathrm{F}} \operatorname{APR}_{\mathrm{F}}\left[1-\prod_{\mathrm{A}}\left(1-\mathrm{AR}_{\mathrm{A}}\right)\right], \\
\mathbf{m}_{\mathrm{F}}^{\mathrm{t}}(\{f, \sim f\})=\mathbf{m}_{\mathrm{F}}(\{f, \sim f\}) \mathbf{m}_{\mathrm{F} \leftarrow \text { all }}^{\mathrm{t}}(\sim f)=0, \\
\mathrm{~A}_{\mathrm{s}}(\{f, \sim f\})=\operatorname{IR}_{\mathrm{F}} \operatorname{APR}_{\mathrm{F}}\left[1-\prod_{\mathrm{A}}\left(1-\mathrm{AR}_{\mathrm{A}}\right)\right] .
\end{gathered}
$$

This yields the following values for beliefs and plausibilities that are of interest (using [4], [5] and [B-6]):

$$
\begin{gathered}
\operatorname{Bel}_{\mathrm{F}}^{\mathrm{t}}(f)=1-\operatorname{IR}_{\mathrm{F}} \mathrm{APR}_{\mathrm{F}}\left[1-\prod_{\mathrm{A}}\left(1-\mathrm{AR}_{\mathrm{A}}\right)\right], \\
\operatorname{Bel}_{\mathrm{F}}^{\mathrm{t}}(\sim f)=0, \\
\mathbf{P L}_{\mathrm{F}}^{\mathrm{t}}(\sim f)=\mathrm{AR}_{\mathrm{F}}^{\mathrm{t}}=\operatorname{IR}_{\mathrm{F}} \mathrm{APR}_{\mathrm{F}}\left[1-\prod_{\mathrm{A}}\left(1-\mathrm{AR}_{\mathrm{A}}\right)\right] .
\end{gathered}
$$

Since we termed plausibility of error as audit risk, the desired formula for the audit risk is given by $\mathrm{AR}_{\mathrm{F}}^{\mathrm{t}}$ in $(\mathrm{B}-7)$, where $\mathrm{AR}_{\mathrm{A}}=\mathrm{IR}_{\mathrm{A}} \mathrm{APR}_{\mathrm{A}}\left[1-\prod\left(1-\mathrm{AR}_{\mathrm{AO}}\right)\right]$ as defined in (B-4) and $\mathrm{AR}_{\mathrm{AO}}=\mathrm{IR}_{\mathrm{AO}} \mathrm{APR}_{\mathrm{AO}} \mathrm{CR}_{\mathrm{AO}} \mathrm{DR}_{\mathrm{AO}}$ as defined in (16).

\section{Accounts Level}

In this section, we derive a formula for the total plausibility of material misstatement, or the total audit risk, at the account level. Similar to the procedure for deriving the formula for the financial statement level, this derivation combines the eight items of evidence: four at the audit objective level, two at the account level and two at the financial statement level. This will be 
achieved by propagating $\mathbf{m}$-values from $\mathrm{F}$, from the audit objectives, and from other accounts to the desired account. We will use the relationships developed in appendix A. 


\section{Figure 3}

\section{Propagation of $\mathrm{m}$-Values from the Financial Statement and}

Audit Objectives to the Accounts

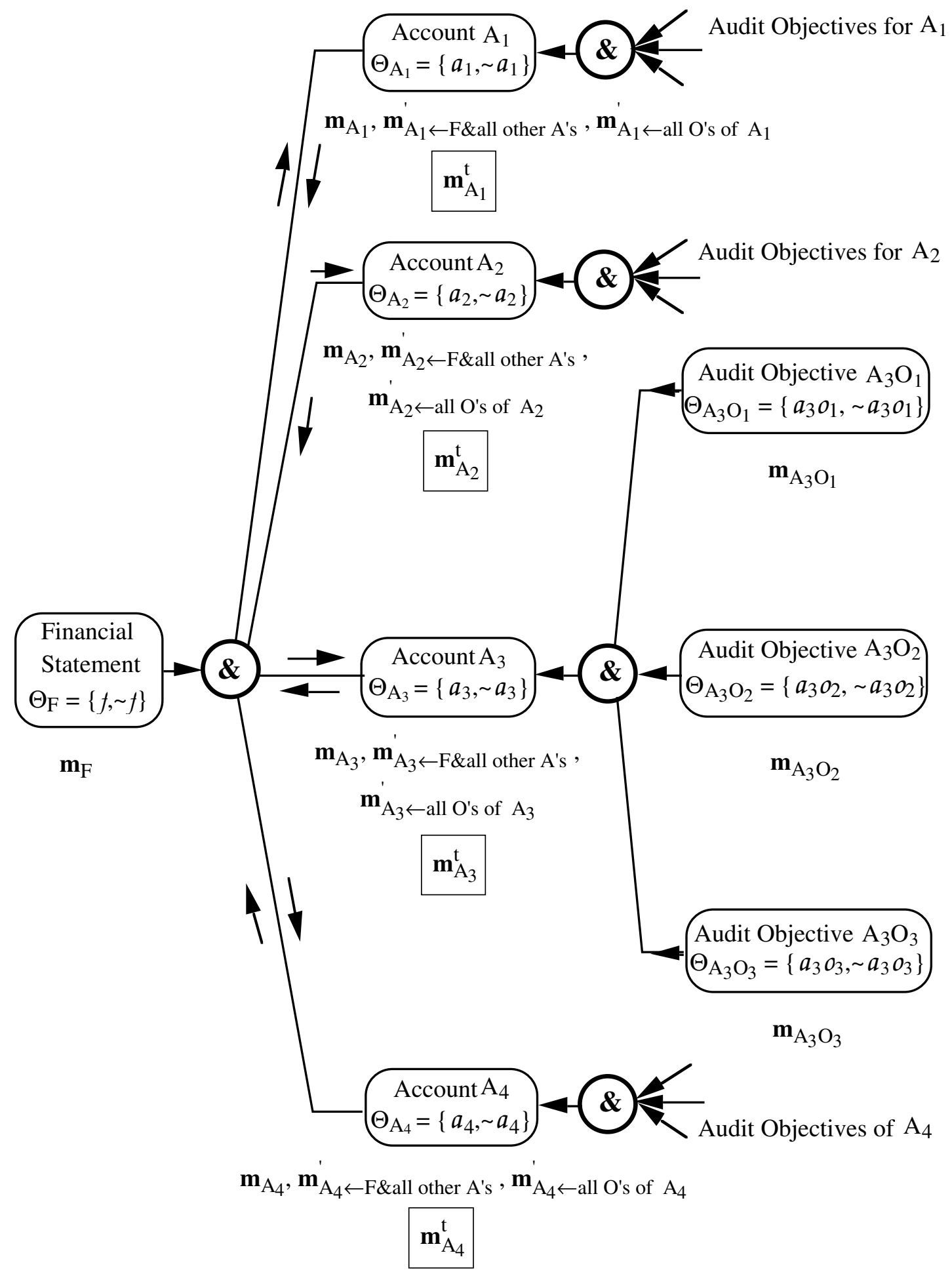


Let us consider, for the purpose of illustration, account $\mathrm{A}_{3}$ in figure 3 . The $\mathbf{m}$-values received by $\mathrm{A}_{3}$ from the audit objectives were determined in the previous section (B-1). The $\mathbf{m}$ values received from the financial statement node is given below (use [8]-[10], [A-7], [A-9] and [A-10]):

$$
\begin{gathered}
\mathbf{m}_{\mathrm{A}_{3} \leftarrow \mathrm{F} \& \text { all other A's }}^{\prime}\left(a_{3}\right)=\mathbf{m}_{\mathrm{F}}(f)=1-\operatorname{IR}_{\mathrm{F}} \mathrm{APR}_{\mathrm{F}}, \\
\mathbf{m}_{\mathrm{A}_{3} \leftarrow \mathrm{F} \& \text { all other A's }}^{\prime}\left(\sim a_{3}\right)=0, \\
\mathbf{m}_{\mathrm{A}_{3} \leftarrow \mathrm{F} \& \text { all other A's }}^{\prime}\left(\left\{a_{3}, \sim a_{3}\right\}\right)=1-\mathbf{m}_{\mathrm{F}}(f)=\operatorname{IR}_{\mathrm{F}} \mathrm{APR}_{\mathrm{F}} .
\end{gathered}
$$

Similar $\mathbf{m}$-values will be received by the other accounts. At $\mathrm{A}_{3}$, we now have three $\mathbf{m}$ values: $\mathbf{m}_{\mathrm{A}_{3}}$ defined at $\mathrm{A}_{3}$ ([11]-[13] ), $\mathbf{m}_{\mathrm{A}_{3} \leftarrow \mathrm{F} \& \text { all other A's }}$ as given in (B-8), and $\mathbf{m}_{\mathrm{A}_{3} \leftarrow \text { all O's of } \mathrm{A}_{3}}^{\prime}$ in (B-1). We combine these $\mathbf{m}$-values using Demspter's rule, which yields the following total $\mathbf{m}$-values:

$$
\begin{gathered}
\mathbf{m}_{\mathrm{A}_{3}}^{\mathrm{t}}\left(a_{3}\right)=1-\operatorname{IR}_{\mathrm{F}} \mathrm{APR}_{\mathrm{F}} \operatorname{IR}_{\mathrm{A}_{3}} \operatorname{APR}_{\mathrm{A}_{3}}\left[1-\prod_{\mathrm{i}=1}^{3}\left(1-\mathrm{AR}_{\mathrm{A}_{3} \mathrm{O}_{\mathrm{i}}}\right)\right], \\
\mathbf{m}_{\mathrm{A}_{3}}^{\mathrm{t}}\left(\sim a_{3}\right)=0, \\
\mathbf{m}_{\mathrm{A}_{3}}^{\mathrm{t}}\left(\left\{a_{3}, \sim a_{3}\right\}\right)=\operatorname{IR}_{\mathrm{F}} \mathrm{APR}_{\mathrm{F}} \operatorname{IR}_{\mathrm{A}_{3}} \mathrm{APR}_{\mathrm{A}_{3}}\left[1-\prod_{\mathrm{i}=1}^{3}\left(1-\mathrm{AR}_{\left.\left.\mathrm{A}_{3} \mathrm{O}_{\mathrm{i}}\right)\right] .}\right.\right.
\end{gathered}
$$

In general, one can write (B-9) as:

$$
\begin{gathered}
\mathbf{m}_{\mathrm{A}}^{\mathrm{t}}(a)=1-\operatorname{IR}_{\mathrm{F}} \mathrm{APR}_{\mathrm{F}} \operatorname{IR}_{\mathrm{A}} \mathrm{APR}_{\mathrm{A}}\left[1-\prod_{\mathrm{O}}\left(1-\mathrm{AR}_{\mathrm{AO}}\right)\right], \\
\mathbf{m}_{\mathrm{A}}^{\mathrm{t}}(\sim a)=0, \\
\mathbf{m}_{\mathrm{A}}^{\mathrm{t}}(\{a, \sim a\})=\operatorname{IR}_{\mathrm{F}} \operatorname{APR}_{\mathrm{F}} \operatorname{IR}_{\mathrm{A}} \operatorname{APR}_{\mathrm{A}}\left[1-\prod_{\mathrm{O}}\left(1-\mathrm{AR}_{\mathrm{AO}}\right)\right] .
\end{gathered}
$$

These values yield the following beliefs and plausibility values (using [4], [5] and [B10]):

$$
\begin{gathered}
\operatorname{Bel}{ }_{\mathrm{A}}^{\mathrm{t}}(a)=1-\operatorname{IR}_{\mathrm{F}} \mathrm{APR}_{\mathrm{F}} \operatorname{IR}_{\mathrm{A}} \mathrm{APR}_{\mathrm{A}}\left[1-\prod_{\mathrm{O}}\left(1-\mathrm{AR}_{\mathrm{AO}}\right)\right], \\
\operatorname{Bel}_{\mathrm{A}}^{\mathrm{t}}(\sim a)=0, \\
\operatorname{PL}_{\mathrm{A}}^{\mathrm{t}}(\sim a)=\mathrm{AR}_{\mathrm{A}}^{\mathrm{t}}=\operatorname{IR}_{\mathrm{F}} \mathrm{APR}_{\mathrm{F}} \mathrm{IR}_{\mathrm{A}} \mathrm{APR}_{\mathrm{A}}\left[1-\prod_{\mathrm{O}}\left(1-\mathrm{AR}_{\mathrm{AO}}\right)\right] .
\end{gathered}
$$

Since the total plausibility in $\sim a$ represents the total audit risk, $\mathrm{AR}_{\mathrm{A}}^{\mathrm{t}}$ in $(\mathrm{B}-11)$ is the desired formula at the account level. 


\section{Audit Objective Level}

In this section, we want to combine, again, all the items of evidence in a network in figure 1, but at the audit objective level. First, we propagate $\mathbf{m}$-values from the financial statement node to the accounts. As an illustration, we consider first propagation of $\mathbf{m}_{\mathrm{F}}$ to $\mathrm{A}_{3}$

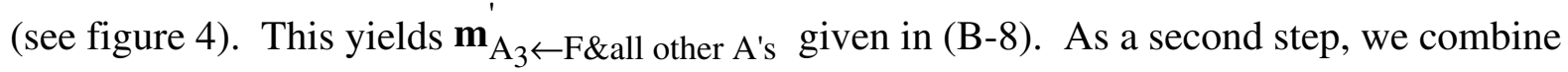
$\mathbf{m}_{\mathrm{A}_{3} \leftarrow \text { F\&all other A's }}^{\prime}$ with $\mathbf{m}_{3}$ at $\mathrm{A}_{3}$ ([11]-[13]). The result of combination yields $\mathbf{m}_{\mathrm{A}_{3}}$ :

$$
\begin{gathered}
\mathbf{m}_{\mathrm{A}_{3}}^{\prime \prime}(a)=1-\mathrm{IR}_{\mathrm{F}} \mathrm{APR}_{\mathrm{F}} \mathrm{IR}_{\mathrm{A}_{3}} \mathrm{APR}_{\mathrm{A}_{3}}, \\
\mathbf{m}_{\mathrm{A}_{3}}^{\prime \prime}(\sim a)=0, \\
\mathbf{m}_{\mathrm{A}_{3}}^{\prime \prime}(\{a, \sim a\})=\operatorname{IR}_{\mathrm{F}} \mathrm{APR}_{\mathrm{F}} \operatorname{IR}_{\mathrm{A}_{3}} \mathrm{APR}_{\mathrm{A}_{3}} .
\end{gathered}
$$




\section{Figure 4}

\section{Propagation of $\mathrm{m}$-Values from the Financial Statement and Accounts to the Audit Objectives}

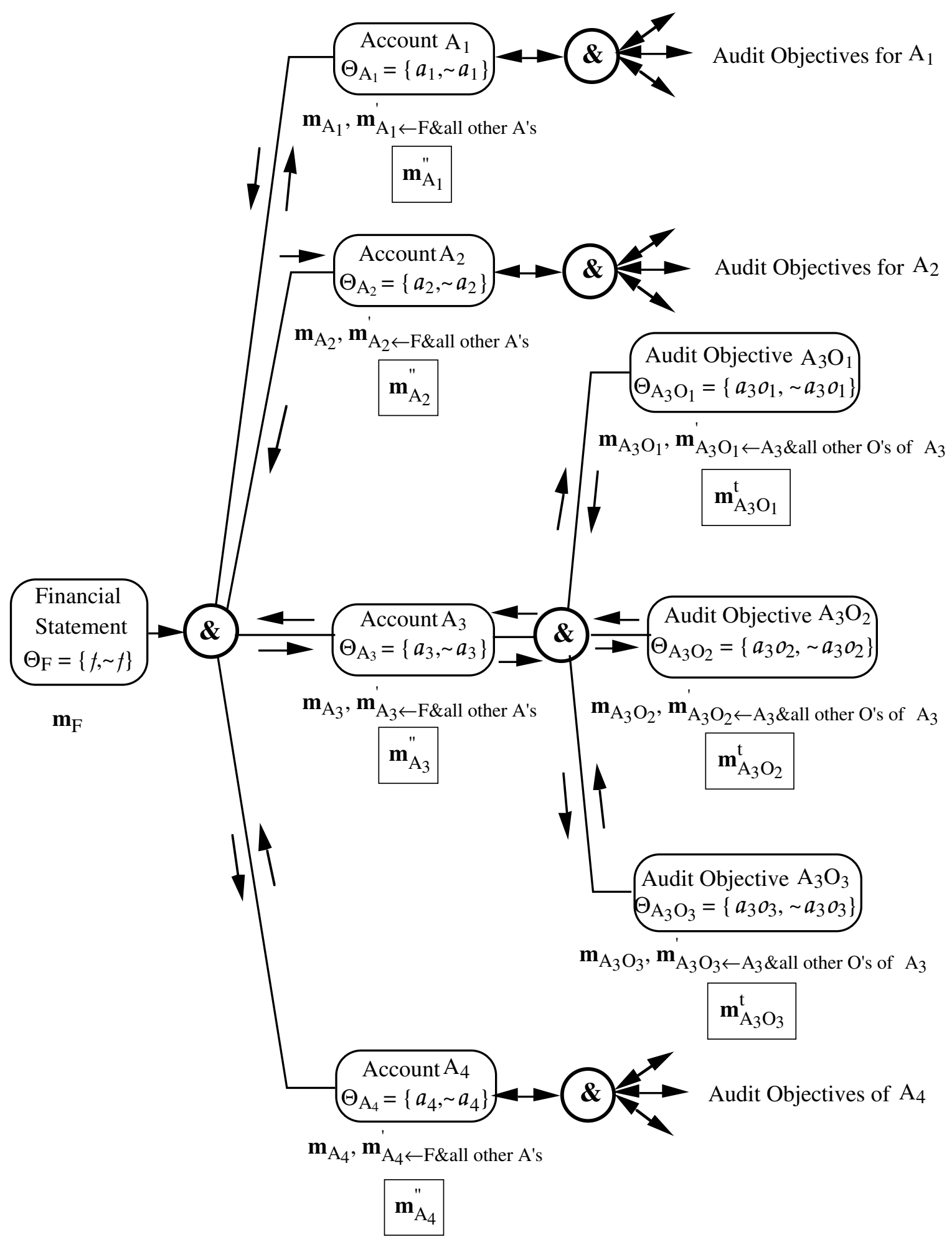


These $\mathbf{m}$-values are propagated to the various audit objectives. We use (A-7), (A-9), and (A-10) for this purpose. For audit objective $\mathrm{A}_{3} \mathrm{O}_{2}$, the result of propagation yields

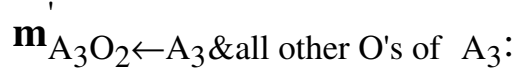

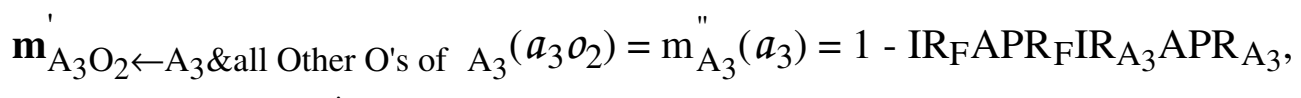

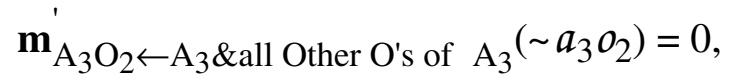

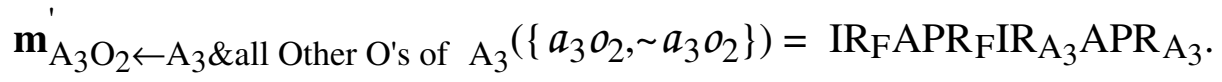

As shown in figure 4, we have two m-values at each audit objective. For objective $\mathrm{O}_{2}$ of

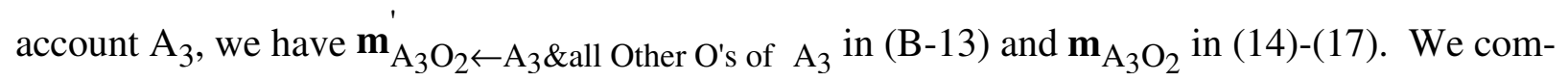
bine these values using Dempster's rule, which yields the total $\mathbf{m}$-values at the audit objective level. This represents an aggregation of all the items of evidence bearing on various levels.

$$
\begin{aligned}
& \mathbf{m}_{\mathrm{A}_{3} \mathrm{O}_{2}}^{\mathrm{t}}\left(a_{3} o_{2}\right)=1-\mathrm{IR}_{\mathrm{F}} \mathrm{APR} \mathrm{FIR}_{\mathrm{A}_{3}} \mathrm{APR}_{\mathrm{A}_{3}} \mathrm{AR}_{\mathrm{A}_{3} \mathrm{O}_{2}} \text {, } \\
& \mathbf{m}_{\mathrm{A}_{3} \mathrm{O}_{2}}^{\mathrm{t}}\left(\sim a_{3} o_{2}\right)=0 \\
& \mathbf{m}_{\mathrm{A}_{3} \mathrm{O}_{2}}^{\mathrm{t}}\left(\left\{a_{3} o_{2}, \sim a_{3} o_{2}\right\}\right)=\operatorname{IR}_{\mathrm{F}} \mathrm{APR}_{\mathrm{F}} \mathrm{IR}_{\mathrm{A}_{3}} \mathrm{APR}_{\mathrm{A}_{3}} \mathrm{AR}_{\mathrm{A}_{3} \mathrm{O}_{2}} \text {. }
\end{aligned}
$$

From (4)-(5), one obtains the following values for beliefs and plausibilities for any audit objective AO:

$$
\begin{gathered}
\text { Bel }{ }_{\mathrm{AO}}^{\mathrm{t}}(a o)=1-\mathrm{IR}_{\mathrm{F}} \mathrm{APR}_{\mathrm{F}} \mathrm{IR}_{\mathrm{A}} \mathrm{APR}_{\mathrm{A}} \mathrm{AR}_{\mathrm{AO}} \\
\mathbf{B e l}_{\mathrm{AO}}^{\mathrm{t}}(\sim a o)=0, \\
\mathbf{P L}_{\mathrm{AO}}^{\mathrm{t}}(\sim a o)=\mathrm{AR}_{\mathrm{AO}}^{\mathrm{t}}=\mathrm{IR}_{\mathrm{F}} \mathrm{APR}_{\mathrm{F}} \mathrm{IR}_{\mathrm{A}} \mathrm{APR}_{\mathrm{A}} \mathrm{AR}_{\mathrm{AO}} .
\end{gathered}
$$

Equation (B-17) is the desired formula for this case. 